\title{
Prospective association of liver function biomarkers with development of hepatobiliary cancers
}

Magdalena Stepien, ${ }^{1}$ Veronika Fedirko, ${ }^{2}$ Talita Duarte-Salles, ${ }^{1}$ Pietro Ferrari, ${ }^{1}$ Heinz Freisling, ${ }^{1}$ Elisabeth Trepo,

${ }^{3}$ Antonia Trichopoulou, $, 45,6$ Christina Bamia, ${ }^{4,5}$ Elisabete Weiderpass, ${ }^{7,8,9,10}$ Anja Olsen, ${ }^{11}$ Anne Tjønneland, ${ }^{11}$

Kim Overvad, ${ }^{12}$ Marie-Christine Boutron-Ruault, ${ }^{13,14,15}$ Guy Fagherazzi, ${ }^{13,14,15}$ Antoine Racine, ${ }^{13,14,15}$ Tilman

Kühn, ${ }^{16}$ Rudolf Kaaks, ${ }^{16}$ Krasimira Aleksandrova, ${ }^{17}$ Heiner Boeing, ${ }^{17}$ Pagona Lagiou, ${ }^{5,6,18}$ Vassiliki Benetou, 4,5

Dimitrios Trichopoulos, $, 4,6,18,19 \dagger$ Domenico Palli, ${ }^{20}$ Sara Grioni, ${ }^{21}$ Rosario Tumino, ${ }^{22}$ Alessio Naccarati, ${ }^{23}$

Salvatore Panico, ${ }^{24}$ H.Bas. Bueno-de-Mesquita, ${ }^{25,26,27,28}$ Petra H Peeters, ${ }^{29}$ Eiliv Lund, ${ }^{30}$ J. Ramón Quirós, ${ }^{31}$ Osmel

Companioni Nápoles, ${ }^{32}$ María-José Sánchez ${ }^{33,34}$ Miren Dorronsoro, ${ }^{35}$ José María Huerta, ${ }^{34,36}$ Eva Ardanaz, ${ }^{34,37}$

Bodil Ohlsson, ${ }^{38}$ Klas Sjöberg, ${ }^{38,39}$ Mårten Werner, ${ }^{40}$ Hanna Nystrom, ${ }^{41}$ Kay-Tee Khaw, ${ }^{42}$ Timothy J Key, ${ }^{43}$

Marc Gunter, ${ }^{44}$ Amanda Cross, ${ }^{44}$ Elio Riboli, ${ }^{44}$ Isabelle Romieu, ${ }^{1}$ and Mazda Jenab, ${ }^{1 *}$

1 Nutrition and Metabolism Section, International Agency for Research on Cancer (IARC-WHO), Lyon, France

2 Rollins School of Public Health, Winship Cancer Institute, Emory University, Atlanta, USA

3 Laboratoire Lyon République, Lyon, France

4 Hellenic Health Foundation, Athens, Greece

5 Department of Hygiene, Epidemiology and Medical Statistics, University of Athens Medical School, Athens,

Greece

6 Bureau of Epidemiologic Research, Academy of Athens, Athens, Greece

7 Department of Community Medicine, Faculty of Health Sciences, University of Tromsø, The Arctic University of

Norway, Tromsø, Norway

8 Department of Research, Cancer Registry of Norway, Oslo, Norway

9 Department of Medical Epidemiology and Biostatistics, Karolinska Institutet, Stockholm, Sweden

10 Samfundet Folkhälsan, Helsinki, Finland

11 Diet, Genes and Environment, Danish Cancer Society Research Center, Copenhagen, Denmark

12 Department of Public Health, Section for Epidemiology, Aarhus, Aarhus University, Denmark

13 Inserm, Centre for research in Epidemiology and Population Health (CESP), U1018, Nutrition, Hormones and

Women's Health team, Villejuif, France

14 Université Paris Sud, UMRS 1018, Villejuif, France

15 Institut Gustave Roussy, Villejuif, France

16 Department of Cancer Epidemiology, German Cancer Research Centre, Heidelberg, Germany

17 Department of Epidemiology, German Institute of Human Nutrition, Potsdam-Rehbruecke, Nuthetal, Germany 
19 Hellenic Health Foundation, Department of Hygiene, Epidemiology and Medical Statistics, University of Athens Medical School, Athens, Greece

20 Molecular and Nutritional Epidemiology Unit, Cancer Research and Prevention Institute - ISPO, Florence, Italy

21 Epidemiology and Prevention Unit, Fondazione IRCCS Istituto Nazionale dei Tumori, Milan, Italy

22 Cancer Registry and Histopathology Unit, "Civic - M.P. Arezzo" Hospital, ASP Ragusa, Italy

23 Molecular and Genetic Epidemiology Unit, HuGeF, Human Genetics Foundation, Torino, Italy

24 Dipartamento di Medicina Clinicae Chirurgias, Federico II University, Naples, Italy

25 Dt. for Determinants of Chronic Diseases (DCD), National Institute for Public Health and the Environment (RIVM), Bilthoven, The Netherlands

26 Dt. of Gastroenterology and Hepatology, University Medical Centre, Utrecht, The Netherlands,

27 Dt. of Epidemiology and Biostatistics, The School of Public Health, Imperial College London, London, United Kingdom

28 Dt. of Social \& Preventive Medicine, Faculty of Medicine, University of Malaya, Kuala Lumpur, Malaysia.

29 Department of Epidemiology, Julius Center for Health Sciences and Primary Care, University Medical Center, Utrecht, The Netherlands

30 Department of Community Medicine, Faculty of Health Sciences, UiT The Arctic University of Norway, Tromso, Norway

31 Public Health Directorate, Asturias, Spain.

32 Unit of Nutrition, Environment and Cancer, Catalan Institute of Oncology, Barcelona, Spain.

33 Escuela Andaluza de Salud Pública. Instituto de Investigación Biosanitaria ibs.GRANADA. Hospitales

Universitarios de Granada/Universidad de Granada, Granada, Spain

34 CIBER Epidemiology and Public Health- CIBERESP, Spain

35 Public Health Direction and Biodonostia-Ciberesp, Basque Regional Health Department, San Sebastian, Spain 36 Department of Epidemiology, Murcia Regional Health Council, IMIB-Arrixaca, Murcia, Spain

37 Navarre Public Health Institute, Pamplona, Spain

38 Department of Clinical Sciences, Division of Internal Medicine, SUS Malmö, Lund University, Malmo, Sweden 39 Department of Gastroenterology and Nutrition, Skåne University Hospital, Malmö, Sweden

40 Department of public health and clinical medicine, Umeå University, Umea, Sweden

41 Department of Surgery, Department of perioperative and surgical sciences, Umea University, Umea, Sweden 42 University of Cambridge School of Clinical Medicine, Clinical Gerontology, Cambridge, United Kingdom 43 Cancer Epidemiology Unit, Nuffield Department of Population Health University of Oxford, Oxford, United Kingdom 
6544 Department of Epidemiology and Biostatistics, School of Public Health, Faculty of Medicine, Imperial College, $66 \quad$ London, United Kingdom

67

68

+ Deceased

69

70

* Corresponding author:

71

Mazda Jenab, $\mathrm{PhD}$

Scientist, Section of Nutrition and Metabolism, International Agency for Research on Cancer (IARC-WHO), Lyon,

France, Tel: +33-(0)472738082, Fax : +33-(0)472738361

Email: jenabm@iarc.fr

75

76

Word count: 4010/ 3000 
ABSTRACT

Introduction: Serum liver biomarkers (gamma-glutamyl transferase, GGT; alanine aminotransferase, ALT; aspartate aminotransferase, AST; alkaline phosphatase, ALP; total bilirubin) are used as indicators of liver disease, but there is currently little data on their prospective association with risk of hepatobiliary cancers.

Methods: A nested-case control study was conducted within the prospective EPIC cohort ( $>520,000$ participants, 10 European countries). After a mean 7.5 mean years of follow-up, 121 hepatocellular carcinoma (HCC), 34 intrahepatic bile duct (IHBC) and 131 gallbladder and biliary tract (GBTC) cases were identified and matched to 2 controls each. Circulating biomarkers were measured in serum taken at recruitment into the cohort, prior to cancer diagnosis. Multivariable adjusted conditional logistic regression was used to calculate odds ratios and $95 \%$ confidence intervals $(\mathrm{OR} ; 95 \% \mathrm{CI})$.

Results: In multivariable models, 1SD increase of each log-transformed biomarker was positively associated with HCC risk $(\mathrm{OR}(\mathrm{GGT})=4.23,95 \% \mathrm{CI}: 2.72-6.59 ; \mathrm{OR}(\mathrm{ALP})=3.43,95 \% \mathrm{CI}: 2.31-5.10 ; \mathrm{OR}(\mathrm{AST})=3.00,95 \% \mathrm{CI}: 2.04-4.42$; $\mathrm{OR}(\mathrm{ALT})=2.69,95 \% \mathrm{CI}: 1.89-3.84 ;$ OR(Bilirubin $)=2.25,95 \% \mathrm{CI}: 1.58-3.20)$. Each liver enzyme $(\mathrm{OR}(\mathrm{GGT})=4.98$; 95\%CI:1.75-14.17; OR(AST)=3.10，95\%CI:1.04-9.30; OR(ALT)=2.86, 95\%CI:1.26-6.48, OR(ALP)=2.31， 95\%CI:1.10-4.86) but not bilirubin (OR(Bilirubin) $=1.46,95 \% \mathrm{CI}: 0.85-2.51)$ showed a significant association with IHBC. Only ALP was significantly associated with GBTC risk (OR(ALP)=1.59, 95\%CI:1.20-2.09).

Conclusion: This study shows positive associations between circulating liver biomarkers in sera collected prior to cancer diagnoses and the risks of developing HCC or IHBC, but not GBTC.

Keywords: Hepatobiliary Cancer, Liver Function Test, Biological Markers, Prospective Cohort, Nested Casecontrol Study 


\section{INTRODUCTION}

Liver cancer is the sixth most commonly diagnosed cancer and the second leading cause of cancer death worldwide [1]. Hepatocellular carcinoma (HCC), the most common type of primary liver cancer, is diagnosed at late stages and characterised by a poor prognosis [2]. Established HCC risk factors are chronic hepatitis B and C virus (HBV/HCV) infection, heavy alcohol drinking leading to liver cirrhosis, smoking and dietary aflatoxin exposure [3]. Important evidence from prospective studies also supports a role for diabetes and obesity-associated non-alcoholic fatty liver disease (NAFLD) as important HCC risk factors [4,5]. The group of intrahepatic bile duct (IHBC) and biliary tract cancers (GBTC; tumours of the gall bladder and extra-hepatic bile ducts) are anatomically related to HCC. They too are often diagnosed at late stages when prognosis is poor, also with little existing information about their key determinants [6].

Liver function biomarkers (gamma-glutamyl transferase, GGT; alanine aminotransferase, ALT; aspartate aminotransferase, AST; alkaline phosphatase, ALP; total bilirubin) are used in clinical diagnosis of various disorders, including those related to liver function impairment and damage. Higher levels of specific combinations of these liver function biomarkers have been shown to be independently associated with NAFLD, liver cirrhosis, hepatitis infection, biliary obstruction [7] and diabetes risk [8,9], which is itself also associated with increased risk of HCC [10]. Previous case-control studies have found that GGT, ALT and AST are increased in approximately $90 \%$ of diagnosed HCC cases while half of the cases also showed elevated liver-specific alkaline phosphatase (ALP) or bilirubin levels [11]. For bile duct cancers, the sparse available data suggest that approximately $70 \%$ of cases have elevated levels of ALP and GGT [12]. It is thus possible that alterations in liver function biomarkers occur during the early development of hepatobiliary cancers and may relate to some of the underlying mechanisms of tumour development at these sites. In a recent systematic review GGT but not ALT was associated with increased risk of overall and liver cancer but the geographical variations were observed for ALT [13]. Existing prospective observational studies investigating the association between liver function biomarkers and liver cancers have been mostly based on Asian populations [14,15], and/or limited only to particular enzymes (either transaminases, ALT and AST, or GGT) [16,17]. A cohort study based on a mostly hepatitis negative Taiwanese subjects measured only transaminases and found that both enzymes were good independent predictors for HCC development [16]. Other studies based on hepatitis infected Asian populations have found positive HCC risk associations with many liver enzymes, but not bilirubin $[14,15]$. In a Swedish cohort, higher GGT levels were prospectively associated with increased risk for several cancer sites, including cancer in the liver, suggesting that this individual enzyme is not specific to disease in the liver and biliary tract [17]. However, there is currently little prospective data on this topic from additional Western populations where chronic hepatitis infections are less predominant while other HCC risk 
factors such as excessive alcohol intake, obesity or diabetes are common. Very little is known about possible associations with IHBC or GBTC, particularly from prospective cohort settings.

To address this, we aimed to evaluate associations between risk of HCC, IHBC and GBTC and five commonly measured liver function biomarkers (GGT, ALT, AST, ALP and bilirubin) using a nested case-control study within the large European Prospective Investigation into Cancer and Nutrition (EPIC) cohort,.

\section{MATERIALS AND METHODS}

\subsection{Study design}

EPIC is a large multicentre prospective cohort study designed to investigate the association between diet, lifestyle and environmental factors and the incidence of various types of cancer and other chronic diseases. The rationale, study design and methods of recruitment are described in detail elsewhere $[18,19]$. Briefly, diet and lifestyle data were collected from approximately 520,000 men and women aged 20-85 years enrolled between 1992 and 2000 in 23 centres throughout 10 European countries: Denmark, France, Germany, Greece, Italy, Norway, Spain, Sweden, the Netherlands, and United Kingdom [18]. Blood samples were collected from most participants at recruitment and are stored at the International Agency for Research on Cancer (IARC, Lyon, France) in $-196^{\circ} \mathrm{C}$ liquid nitrogen for all countries except Denmark $\left(-150^{\circ} \mathrm{C}\right.$, nitrogen vapour) and Sweden $\left(-80^{\circ} \mathrm{C}\right.$, freezers). Study participants were recruited from the general population residing in a given geographical area, except for the Ragusa cohort (blood donors and their spouses), the Utrecht cohort (women attending a breast cancer screening), and the Oxford health conscious sub-cohort (mostly vegetarian and health-conscious volunteers).

All cohort members provided written informed consent. Approval for this study was obtained from the relevant ethical review boards of the participating institutions and from the IARC ethical review board (Lyon, France).

\subsection{Follow-up for cancer incidence and mortality}

Vital status follow-up (98.5\% complete) was collected by record linkage with regional and/or national mortality registries in all countries except Germany and Greece, where follow-up was based on active follow-up through study subjects or their next-of-kin. Cancer incidence was determined through record linkage with regional cancer registries (Denmark, Italy, Netherlands, Norway, Spain, Sweden and United Kingdom; complete up to December 2006) or via a combination of methods, including the use of health insurance records, contacts with cancer and pathology registries, and active follow-up through study subjects and their next-of-kin (France, Germany, Greece; complete up to June 2010).

\subsection{Case Ascertainment}

According to the $10^{\text {th }}$ revision of the International Statistical Classification of Diseases, Injury and Causes of Death (ICD10) HCC and IHBC were defined as C22.0 and C22.1, respectively. Biliary tract cancers (GBTC) included 
tumours in the gallbladder (C23.9), extrahepatic bile ducts (C24.0), ampulla of Vater (C24.1), and biliary tract (C24.8 and C24.9). For each identified case, the histology and the methods used to diagnose the cancer were reviewed to exclude metastatic cases or other types of primary liver cancer.

\subsection{Nested Case-Control Study Design}

The design of the nested case-control study has been previously described in detail [20]. Briefly, 125 HCC, 35 IHBC and 137 GBTC cases were identified during the period between participants' recruitment and 2006 in EPIC. For each case, two controls were selected by incidence density sampling from all cohort members alive and free of cancer (except non-melanoma skin cancer), and matched by age at blood collection ( \pm 1 year), sex, study center, time of the day at blood collection ( \pm 3 hours), fasting status at blood collection $(<3,3-6$, and $>6$ hours); among women, additionally by menopausal status (pre-, peri-, and postmenopausal), and hormone replacement therapy use at time of blood collection (yes/no).

\subsection{Biomarker measures}

Hepatitis B and C virus seropositivity was detected in all case-control sets using the ARCHITECT HBsAg and anti$\mathrm{HCV}$ chemiluminescent microparticle immunoassays (CMIAs) from Abbott Diagnostics (Rungis, France). Creactive protein (CRP), AFP, GGT, ALT, AST, ALP, total bilirubin and albumin were measured on the ARCHITECT c Systems ${ }^{\mathrm{TM}}$ and the AEROSET System (Abbott Diagnostics, Rungis, France) using standard protocols. All laboratory analyses were performed at the Centre de Biologie République laboratory, Lyon, France. Participants with missing blood sample or failed laboratory assay were excluded (n=4, 1, 6 for HCC, IHBC and GBTC, respectively). Therefore, the final sample size included 568 controls and 286 cases, among which there were $121 \mathrm{HCC}, 34 \mathrm{IHBC}$ and 131 GBTC cases.

\subsection{Statistical Analyses}

Description of methods used for comparisons of baseline subjects characteristics, correlation and visualisation of biomarker levers over follow up time are described in electronic supplementary material.

Conditional logistic regression models were used to calculate odds ratios (OR) and 95\% confidence intervals (CI) for serum individual biomarkers of interest (GGT, ALT, AST, ALP and bilirubin) in relation to HCC, IHBC and GBTC. Each main variable was included in models as categorical variables, with quartile cut-points based on sexspecific distributions among controls (for HCC and GBTC) and continuous z-standardised (Mean=0, $\mathrm{SD}=1$ ) value of each log-transformed biomarker for all cancer sites (to enable direct comparison between the biomarkers). To test dose-responses, trend variables were assigned the sex-specific median values for overall quartiles of the biomarkers. Cubic splines were constructed to illustrate the dose-response association between biomarker levels and HCC risk. In addition, specific ratios (AST/ALT; GGT/ALP), hepatic steatosis index (HSI) and score (see Table 1 footnotes), 
and a score based on liver function biomarkers were calculated as described in more detail in supplementary material.

For HCC, three conditional logistic models were used as follows: model 1) a model based on matching factors only; model 2) a multivariable model incorporating additional adjustments for a priori defined confounders: smoking status (never, former, current, missing), baseline (continuous, g/d) and lifetime alcohol intake pattern (never, former, lifetime drinker and drinker only at recruitment), body mass index (BMI, continuous $\mathrm{kg} / \mathrm{m}^{2}$ ), and physical activity (active, inactive, missing); model 3) a more detailed multivariable model incorporating the above variables as well as positivity status for hepatitis B and or $\mathrm{C}$ infection (yes, no, missing). Additionally, models 4 and 5 with separate incorporation of prevalent diabetes status at baseline and CRP to model 2 were explored.

For IHBC and GBTC, only models 1 and 2 were considered, and a third model for GBTC with the additional adjustment for self-reported history of gallstones was run. Other potential confounders examined, but not included in the final models because their inclusion did not change the effect estimates by more than $10 \%$ were waist to hip ratio (WHR), coffee intake, and reported cardiovascular disease for HCC and IHBC or self-reported history of gallstones for GBTC.

In sensitivity analyses, we excluded subjects with (a) self-reported diabetes at baseline (yes/no), because of the potential for modifications in diet after diagnosis of this disease, (b) hepatitis infection, since it is an established risk factor for liver cancers, (c) subjects with follow-up of $<2 / 4$ years after blood collection to exclude possible reverse causation, d) those with abnormal value of transaminases.

For HCC, potential effect modification was studied for BMI, WHR and self-reported diabetes at baseline (since liver enzyme activity have been shown to increase in obesity and diabetes [22]), HSI score, smoking and alcohol intake (associated with liver cirrhosis [23]) and CRP, as a marker of chronic inflammation. Effect modification by these variables was tested on the multiplicative scale by including interaction terms formed by the product of modifying variable categories (see footnotes Table 1) and the value of categories of biomarkers. The statistical significance of interactions was assessed using likelihood ratio tests based on the models with and without the interaction terms. In our population only 21 cases and 12 controls within the same case-control sets had HSI below 30, a threshold for those that NAFLD can be ruled out [21], and statistical analyses were not possible in this sub-group.

Receiver operating characteristics (ROC) curves were constructed for each individual biomarker of interest and their combinations in order to assess their discriminatory performance between cases and controls, for all subjects and stratified by HSI (see supplementary material). All statistical tests were two-sided, and $P$-values $<0.05$ were considered statistically significant. All statistical analyses were conducted using SAS version 9.2 software (SAS Institute, Inc., Cary, NC, USA).

\section{RESULTS}


Selected baseline characteristics of cancer cases and their matched controls and correlations between variables are presented in Table 1 and Supplementary Tables 1 and 2. Supplementary Fig. 1 illustrates differences in biomarker levels between cases and controls over time. For the description see supplementary file.

Table 1. Baseline demographic and lifestyle characteristics of HCC $(N=121)$, intrahepatic $(N=34)$ and extrahepatic $(N=$ 131) bile duct cancer cases and their matched controls in the EPIC nested case-control study.

\begin{tabular}{|c|c|c|c|c|c|c|}
\hline \multirow{2}{*}{ Characteristics } & \multicolumn{2}{|c|}{$\begin{array}{l}\text { Hepatocellular Carcinoma } \\
\text { (HCC) }\end{array}$} & \multicolumn{2}{|c|}{$\begin{array}{c}\text { Tumours of the Intrahepatic } \\
\text { Bile Ducts (IHBC) }\end{array}$} & \multicolumn{2}{|c|}{$\begin{array}{l}\text { Tumours of the Gallbladder } \\
\text { and Extrahepatic Bile Ducts } \\
\text { (GBTC) }\end{array}$} \\
\hline & $\begin{array}{l}\text { Cases } \\
(\mathrm{N}=121)\end{array}$ & $\begin{array}{l}\text { Matched } \\
\text { controls } \\
(\mathbf{N}=\mathbf{2 4 2}) \\
\end{array}$ & $\begin{array}{l}\text { Cases } \\
(N=34)\end{array}$ & $\begin{array}{l}\text { Matched } \\
\text { controls } \\
(\mathbf{N}=67) \\
\end{array}$ & Cases $(\mathrm{N}=131)$ & $\begin{array}{l}\text { Matched } \\
\text { controls } \\
(\mathrm{N}=259) \\
\end{array}$ \\
\hline Men, N (\%) & $82(67.8)$ & $165(68.2)$ & $18(52.9)$ & $35(52.2)$ & $58(44.3)$ & $112(43.2)$ \\
\hline Age at blood donation (y) & $60.2 \pm 6.5$ & $60 \pm 6.7$ & $61.6 \pm 6.3$ & $61.6 \pm 6.2$ & $58.6 \pm 7.5$ & $58.6 \pm 7.5$ \\
\hline $\begin{array}{l}\text { Follow-up from blood collection } \\
\text { (y) } \\
\text { Liver function and inflammatory }\end{array}$ & $\begin{array}{l}4.99 \pm 2.9 \\
\text { omarkers, med }\end{array}$ & $(5$ th, 95 th $\%)$ & $4.15 \pm 2.21$ & - & $5 \pm 2.9$ & - \\
\hline $\begin{array}{l}\text { Gamma-glutamyl transferase } \\
\text { (GGT), U/L }\end{array}$ & $84(13,742)$ & $23.5(10,74)$ & $44(13,595)$ & $21(11,89)$ & $23(10,99)$ & $20(10,79)$ \\
\hline $\begin{array}{l}\text { Alanine aminotransferase } \\
(\mathrm{ALT}), \mathrm{U} / \mathrm{L}\end{array}$ & $30(10,151)$ & $17(9,45)$ & $20(12,99)$ & $16(9,32)$ & $17(9,39)$ & $17(9,39)$ \\
\hline $\begin{array}{l}\text { Aspartate aminotransferase } \\
\text { (AST), U/L }\end{array}$ & $43(14,152)$ & $19(13,35)$ & $21(15,83)$ & $18(12,26)$ & $19(12,31)$ & $18(13,30)$ \\
\hline $\begin{array}{l}\text { Alkaline phosphatase (ALP), } \\
\text { U/L }\end{array}$ & $84(44,173)$ & $60(38,100)$ & $74(44,380)$ & $66(41,100)$ & $66(39,110)$ & $60(36,91)$ \\
\hline Total billirubin, $\mu \mathrm{mol} / \mathrm{L}$ & $10(4,32)$ & $7.6(3,15)$ & $7(3,17)$ & $6.7(3,13)$ & $7(4,14)$ & $7(3,15)$ \\
\hline C-reactive protein, $\mathrm{mg} / \mathrm{La}$ & $2(1,27)$ & $2(1,9)$ & $3(1,19)$ & $1(1,9)$ & $2(1,13)$ & $1(1,9)$ \\
\hline \multicolumn{7}{|l|}{ Liver function score, $\mathrm{N}(\%)^{\mathrm{b}}$} \\
\hline 0 & $52(43.0)$ & $231(95.5)$ & $19(55.9)$ & $55(82.1)$ & $111(84.7)$ & $220(85.0)$ \\
\hline$\geq 1$ & $69(57.0)$ & $11(4.5)$ & $15(44.1)$ & $12(17.9)$ & $20(15.3)$ & $39(15.0)$ \\
\hline \multicolumn{7}{|l|}{ AST/ALT ratio, N (\%) } \\
\hline$\leq 2$ & $109(90.1)$ & $236(97.5)$ & $34(100.0)$ & $66(98.5)$ & $125(95.4)$ & $252(97.3)$ \\
\hline$>2$ & $12(9.9)$ & $6(2.5)$ & $0(0.0)$ & $1(1.5)$ & $6(4.6)$ & $7(2.7)$ \\
\hline \multicolumn{7}{|l|}{ GGT/ALP ratio, $\mathrm{N}(\%)$} \\
\hline$\leq 2.5$ & $104(86.0)$ & $238(98.4)$ & $33(97.1)$ & $67(100.0)$ & $130(99.2)$ & $255(98.5)$ \\
\hline$>2.5$ & $17(14.0)$ & $4(1.6)$ & $1(2.9)$ & $0(0.0)$ & $1(0.8)$ & $4(1.5)$ \\
\hline \multicolumn{7}{|l|}{ No. with diabetes $(\mathrm{N}, \%)^{\mathrm{c}, \mathrm{d}}$} \\
\hline No & $101(83.5)$ & $219(90.5)$ & $31(91.2)$ & $61(91.0)$ & $116(88.6)$ & $228(88.0)$ \\
\hline Yes & $16(13.2)$ & $14(5.8)$ & $2(5.9)$ & $4(6.0)$ & $8(6.1)$ & $15(5.8)$ \\
\hline
\end{tabular}

Hepatic steatosis index (HSI; N, $\%)^{\mathrm{e}}$ score 
$\leq 36$ (unlikely NAFLD)

$59(48.8)$

$128(52.9)$

$13(38.2)$

$40(59.7)$

$73(55.7)$

$145(60.0)$

$>36$ (suspected NAFLD)

$58(47.9)$

$105(43.4)$

$21(61.8)$

$25(37.3)$

$51(37.2)$

$98(37.8)$

Anthropometric factors and daily dietary intake, mean \pm SD

$\begin{array}{lcccccc}\begin{array}{l}\text { Body mass index (BMI) }{ }^{\mathrm{f}} \\ \left(\mathrm{kg} / \mathrm{m}^{2}\right)\end{array} & 28.1(5.3) & 27.0(3.9) & 28.2(3.6) & 26.4(4.2) & 26.8(4.5) & 26.4(3.8) \\ \text { Waist-to-hip ratio (WHR) } & 0.93(0.10) & 0.91(0.10) & 0.90(0.08) & 0.89(0.10) & 0.88(0.10) & 0.87(0.10) \\ & 2147.5 \pm & 2212.3 \pm & 2130.2 \pm & 1999.6 \pm & & 2089.3 \pm \\ & 644.0 & 567.1 & 671.8 & 578.6 & & 570.9 \\ \text { Energy (kcal) } & 19.7 \pm 29.4 & 14.8 \pm 18.2 & 14.1 \pm 17.5 & 14.4 \pm 18.1 & 13.4 \pm 18.6 & 14.2 \pm 18.6 \\ & 398.2 \pm 445.9 & 449.1 \pm 434.8 & 398.1 \pm 347.6 & 378.2 \pm 359.8 & 378.8 \pm 366.6 & 441.9 \pm 411.3\end{array}$

Missing values were not excluded from percentage calculations, thus the sum of percents across sub-groups may not add up to $100 \%$. Categorical variables are presented as numbers (percentages).

Continuous variables are presented as mean \pm standard deviations, except for liver function tests that are presented as median and (5th, $95^{\text {th }}$ percentile).

${ }^{a}$ CRP category: $\leq 3>$

${ }^{\mathrm{b}}$ Ranges from 0 to 6; was grouped in categories as $0,1-2, \geq 3$ abnormal liver function tests (ALT>55 U/L, AST>34 U/L, GGT men >64 $\mathrm{U} / \mathrm{L}$, GGT women $>36 \mathrm{U} / \mathrm{L}, \mathrm{ALP}>150 \mathrm{U} / \mathrm{L}$, albumin $<34 \mathrm{~g} / \mathrm{L}$, total bilirubin $>20.5 \mu \mathrm{mol} / \mathrm{L}$; based on the values provided by the laboratory).

${ }^{\mathrm{c}}$ Self-reported.

${ }^{\mathrm{d}}$ Number of cases and controls with missing variable value: $\mathrm{HCC}=13, \mathrm{IHBC}=3$, and $\mathrm{GBTC}=23$.

${ }^{\mathrm{e}}$ Hepatic steatosis index $(\mathrm{HSI})=8 \mathrm{x}$ ALT/AST ratio $+\mathrm{BMI}(+2$, if diabetes; +2 , if female). Number of cases and controls with missing variable value: $\mathrm{HCC}=13, \mathrm{IHBC}=3$, and $\mathrm{GBTC}=23$.

${ }^{\mathrm{f}}$ BMI categories: $\leq 25$ normal, $25-30$ overweight, $\geq 30$ obese

${ }^{g}$ WHR category: sex-specific tertiles (men: $\leq 0.92,0.92-0.97, \geq 0.97$; women: $\leq 0.77,0.77-0.84, \geq 0.84$ ).

\subsection{Liver function biomarkers and the risk of liver (HCC, IHBC) and biliary tract cancers (GBTC)}

In the analyses by quartiles of serum enzyme levels, for all four enzymes and total bilirubin the highest quartile was significantly positively associated with HCC risk in both models 1 and 2 (Table 2). For model 2 the estimates were attenuated slightly than from those for model 1; comparing the highest quartile to the lowest quartile, the findings from model 2 were as follows: $\mathrm{OR}_{(\mathrm{GGT})}=7.90,95 \% \mathrm{CI}: 2.98-20.98, \mathrm{p}_{\text {trend }}=<0.0001 ; \mathrm{OR}_{(\mathrm{ALT})}=4.62,95 \% \mathrm{CI}: 2.05-10.41$, $\mathrm{p}_{\text {trend }}=<0.0001 ; \mathrm{OR}_{(\mathrm{AST})}=5.00,95 \% \mathrm{CI}: 1.95-12.86, \mathrm{p}_{\text {trend }}=<0.0001 ; \mathrm{OR}_{(\mathrm{ALP})}=6.15,95 \% \mathrm{CI}: 2.32-16.31, \mathrm{p}_{\text {trend }}=<0.0001$, $\mathrm{OR}_{(\mathrm{BILIRUBIN})}=3.22,95 \% \mathrm{CI}: 1.39-7.45, \mathrm{p}_{\text {trend }}=0.0002$. Further adjustment for hepatitis status slightly lowered the risk estimates for all enzymes. Only for ALP the OR was higher: $\mathrm{OR}_{(\mathrm{ALP})}=9.56,95 \% \mathrm{CI}: 2.63-34.72$ and for bilirubin it was no longer significant.

In continuous analyses, statistically significant positive associations were found between all liver enzymes and bilirubin and HCC (fully adjusted OR for 1 SD in log unit increase- model 2) (Table 2). GGT was most strongly related to $\mathrm{HCC}$ risk $\left(\mathrm{OR}_{(\mathrm{GGT})}=4.23,95 \% \mathrm{CI}: 2.72-6.59\right)$, followed by $\mathrm{ALP}\left(\mathrm{OR}_{(\mathrm{ALP})}=3.43,95 \% \mathrm{CI}: 2.31-5.10\right)$, AST $\left(\mathrm{OR}_{(\mathrm{ALP})}=3.00,95 \% \mathrm{CI}: 2.04-4.42\right), \quad \mathrm{ALT}\left(\mathrm{OR}_{(\mathrm{ALT})}=2.69,95 \% \mathrm{CI}: 1.89-3.84\right)$ and bilirubin $\quad\left(\mathrm{OR}_{(\mathrm{BILIRUBIN})}=2.25\right.$, 95\%CI:1.58-3.20). Further adjustment for hepatitis status (model 3) made these associations weaker for most enzymes and bilirubin $\left(\mathrm{OR}_{(\mathrm{GGT})}=3.55,95 \% \mathrm{CI}: 2.26-5.57\right)$, and stronger only for ALP $\left(\mathrm{OR}_{(\mathrm{ALP})}=3.17,95 \%\right.$ CI:2.02-4.98). No 
effect on the estimates was observed after additional adjustment for diabetes status or CRP (data not shown). Cubic splines illustrating dose-response associations between the biomarkers and HCC risk are presented in Fig. 1 (for GGT) and supplementary Fig. 3.

Table 2. The association for HCC risk with individual liver function biomarkers for quartiles and per 1 SD increase of logtransformed values.

\begin{tabular}{|c|c|c|c|c|c|c|}
\hline & Quartile 1 & $\begin{array}{l}\text { Quartile 2 } \\
\text { OR (95\%CI) }\end{array}$ & $\begin{array}{l}\text { Quartile 3 } \\
\text { OR (95\%CI) }\end{array}$ & $\begin{array}{l}\text { Quartile } 4 \\
\text { OR (95\%CI) }\end{array}$ & & $\begin{array}{l}\text { Per } 1 \text { SD* log- } \\
\text { transformed } \\
\text { OR }(95 \% \mathrm{CI})\end{array}$ \\
\hline $\begin{array}{l}\text { No. of cases/ } \\
\text { controls }\end{array}$ & $11 / 60$ & $10 / 59$ & $10 / 56$ & $90 / 67$ & & $121 / 242$ \\
\hline \multicolumn{7}{|l|}{ GGT } \\
\hline Model 1 & 1.00 (Ref) & $1.04(0.38,2.84)$ & $1.06(0.39,2.90)$ & $9.10(3.93,21.10)$ & $<.0001$ & $4.58(3.04,6.90)$ \\
\hline Model 2 & 1.00 (Ref) & $1.16(0.37,3.67)$ & $1.12(0.33,3.76)$ & $7.90(2.98,20.98)$ & $<.0001$ & $4.23(2.72,6.59)$ \\
\hline Model 3 & 1.00 (Ref) & $1.18(0.35,4.02)$ & $1.14(0.33,4.03)$ & $5.70(1.99,16.31)$ & $<.0001$ & $3.55(2.26,5.57)$ \\
\hline
\end{tabular}

ALT

$\begin{array}{lllllll}\text { Model } 1 & 1.00(\text { Ref }) & 0.97(0.41,2.30) & 2.31(1.03,5.21) & 5.10(2.44,10.67) & <.0001 & 2.77(2.03,3.77) \\ \text { Model 2 } & 1.00(\text { Ref }) & 0.77(0.28,2.12) & 1.87(0.74,4.76) & 4.62(2.05,10.41) & <.0001 & 2.69(1.89,3.84) \\ \text { Model } 3 & 1.00(\text { Ref }) & 2.04(0.71,5.85) & 0.79(0.24,2.60) & 3.03(1.14,8.09) & 0.0015 & 2.04(1.40,2.99)\end{array}$

AST

$\begin{array}{lllllll}\text { Model } 1 & 1.00(\text { Ref }) & 1.94(0.76,4.92) & 1.15(0.43,3.06) & 6.27(2.66,14.82) & <.0001 & 3.25(2.31,4.59) \\ \text { Model 2 } & 1.00(\text { Ref }) & 1.96(0.70,5.48) & 0.86(0.28,2.60) & 5.00(1.95,12.86) & <.0001 & 3.00(2.04,4.42) \\ \text { Model 3 } & 1.00(\text { Ref }) & 2.04(0.71,5.85) & 0.79(0.24,2.60) & 3.03(1.14,8.09) & 0.0028 & 3.17(2.02,4.98)\end{array}$

ALP

$\begin{array}{lllllll}\text { Model } 1 & 1.00(\text { Ref }) & 0.80(0.30,2.14) & 1.35(0.55,3.32) & 5.97(2.60,13.67) & <.0001 & 3.85(2.65,5.59) \\ \text { Model } 2 & 1.00(\text { Ref }) & 1.01(0.34,3.02) & 1.82(0.67,4.97) & 6.15(2.32,16.31) & <.0001 & 3.43(2.31,5.10) \\ \text { Model } 3 & 1.00(\text { Ref }) & 1.20(0.33,4.39) & 5.85(1.44,23.81) & 9.56(2.63,34.72) & <.0001 & 2.75(1.81,4.18)\end{array}$

\section{Bilirubin}

$\begin{array}{lllllll}\text { Model } 1 & 1.00(\text { Ref }) & 0.72(0.35,1.52) & 1.03(0.47,2.23) & 2.89(1.44,5.80) & <.0001 & 2.04(1.54,2.70) \\ \text { Model } 2 & 1.00(\text { Ref }) & 0.64(0.27,1.49) & 1.40(0.56,3.48) & 3.22(1.39,7.45) & 0.0002 & 2.25(1.58,3.20) \\ \text { Model } 3 & 1.00(\text { Ref }) & 0.52(0.20,1.35) & 1.04(0.38,2.86) & 2.20(0.88,5.50) & 0.0206 & 2.06(1.40,3.03)\end{array}$

\footnotetext{
Model 1: matching factors: age at blood collection ( \pm 1 year), sex, study center, time of the day at blood collection ( \pm 3 hours), fasting status at blood collection ( $<3,3-6$, and $>6$ hours); among women, additionally by menopausal status (pre-, peri-, and postmenopausal), and hormone replacement therapy use at time of blood collection (yes/no).

Model 2: model $1+$ smoking status (never, former, current, missing), baseline (continuous, $\mathrm{g} / \mathrm{d}$ ) and lifetime alcohol intake pattern (never, former, lifetime drinker and drinker only at recruitment), body mass index (BMI, continuous $\mathrm{kg} / \mathrm{m}^{2}$ ), and physical activity (active, inactive, missing).

Model 3: model $2+$ plus hepatitis

Cut-off values for sex-specific quartiles:
} 
GGT- females $(<14,<=14-18 ;>=18-26,>=26 \mathrm{U} / \mathrm{L})$, males $(<18.5,>=18.5-26.5,>=26.5-41.5,>=41.5 \mathrm{U} / \mathrm{L})$

AST- females $(<15,>=15-18 ;>=18-21,>=21 \mathrm{U} / \mathrm{L})$, males $(<16,>=16-19 ;>=19-24,>=24 \mathrm{U} / \mathrm{L})$

ALP- females $(<51,>=51-64 ;>=64-77,>=77 \mathrm{U} / \mathrm{L})$, males $(<49,>=49-58 ;>=58-68,>=68 \mathrm{U} / \mathrm{L})$

ALT- females $(<11,>=11-15 ;>=15-20,>=20 \mathrm{U} / \mathrm{L})$, males $(<15,>=15-19 ;>=19-26,>=26 \mathrm{U} / \mathrm{L})$

Bilirubin- females $(<5.3,>=5.3-6.7 ;>=6.7-8.5,>=8.5 \mathrm{U} / \mathrm{L})$, males $(<6,>=6-7.75 ;>=7.75-10.2,>=10.2 \mathrm{U} / \mathrm{L})$

$* S D_{\log (G G T)}=1.03, S D_{\log (A L T)}=0.68, S D_{\log (A S T)}=0.61, S D_{\log (A L P)}=0.39, S D_{\log (\text { Bilirubin })}=0.54$

Fig.1 Dose- response association for log-transformed GGT levels and HCC risk. Adjusted OR (solid line) and 95\%CI (dashed lines) were constructed with 3 knots with the reference value set as median.

For IHBC, all of the enzymes but not bilirubin showed a significantly positive association in the multivariable continuous model (model 2: $\mathrm{OR}_{(\mathrm{GGT})}=4.98,95 \% \mathrm{CI}: 1.75-14.17, \mathrm{OR}_{(\mathrm{ALT})}=2.86,95 \% \mathrm{CI}: 1.26-6.48, \mathrm{OR}_{(\mathrm{AST})}=3.10$, 95\%CI:1.04-9.30, OR $(\mathrm{ALP})=2.31,95 \% \mathrm{CI}: 1.10-4.86)$ (Table 3).

Table 3. The association of serum liver enzyme levels with IHBC risk per 1 SD increase of log-transformed values.

\begin{tabular}{|c|c|c|}
\hline & $\begin{array}{l}\text { Model 1 } \\
\text { OR }(95 \% \text { CI })\end{array}$ & $\begin{array}{l}\text { Model } 2 \\
\text { OR }(95 \% \text { CI })\end{array}$ \\
\hline No. of cases/controls & $34 / 67$ & $34 / 67$ \\
\hline GGT & $3.74(1.73,8.11)$ & $4.98(1.75,14.17)$ \\
\hline ALT & $2.55(1.34,4.86)$ & $2.86(1.26,6.48)$ \\
\hline AST & $3.18(1.24,8.13)$ & $3.10(1.04,9.30)$ \\
\hline ALP & $2.24(1.20,4.20)$ & $2.31(1.10,4.86)$ \\
\hline Bilirubin & $1.36(0.87,2.13)$ & $1.46(0.85,2.51)$ \\
\hline \multicolumn{3}{|c|}{ Data are log-transformed and z-standardised to $1 \mathrm{SD}$ and a mean of 0.} \\
\hline \multicolumn{3}{|c|}{$\begin{array}{l}\text { Model 1: matching factors: age at blood collection ( } \pm 1 \text { year), sex, study } \\
\text { center, time of the day at blood collection ( } \pm 3 \text { hours), fasting status at blood } \\
\text { collection }(<3,3-6 \text {, and }>6 \text { hours); among women, additionally by } \\
\text { menopausal status (pre-, peri-, and postmenopausal), and hormone } \\
\text { replacement therapy use at time of blood collection (yes } / \text { no). } \\
\text { Model } 2 \text { : model } 1+\text { smoking status (never, former, current, missing), } \\
\text { baseline (continuous, g/d) and lifetime alcohol intake pattern (never, former, } \\
\text { lifetime drinker and drinker only at recruitment), body mass index (BMI, } \\
\left.\text { continuous } \mathrm{kg} / \mathrm{m}^{2}\right) \text {, and physical activity (active, inactive, missing). } \\
* S D_{\log (\text { GGT })}=0.87, S D_{\log (A L T)}=0.56, S D_{\log (A S T)}=0.45, S D_{\log (A L P)}= \\
0.43, S D_{\log (\text { Bilirubin) })}=0.48\end{array}$} \\
\hline
\end{tabular}

For GBTC, only ALP was significantly associated with higher GBTC risk (model 2: $\mathrm{OR}_{(\mathrm{ALP})}=2.80,95 \% \mathrm{CI}: 1.36$ $5.76, \mathrm{p}_{\text {trend }}=0.144$ for the highest quartile and $\mathrm{OR}_{(\mathrm{ALP})}=1.59,95 \% \mathrm{CI}: 1.20-2.09$ per 1SD increase of log-transformed value) (Table 4).

Table 4. The association for GBTC risk with individual liver function biomarkers for quartiles and per 1 SD increase of log-transformed values. 


\begin{tabular}{|c|c|c|c|c|c|c|}
\hline & Quartile 1 & $\begin{array}{l}\text { Quartile } 2 \\
\text { OR (95\%CI) }\end{array}$ & $\begin{array}{l}\text { Quartile } 3 \\
\text { OR (95\%CI) }\end{array}$ & $\begin{array}{l}\text { Quartile 4 } \\
\text { OR (95\%CI) }\end{array}$ & & $\begin{array}{l}\text { Per } 1 \text { SD log- } \\
\text { transformed } \\
\text { OR }(95 \% \mathrm{CI}) \\
\end{array}$ \\
\hline $\begin{array}{l}\text { No. of } \\
\text { cases/controls } \\
\text { GGT }\end{array}$ & $29 / 62$ & $30 / 72$ & $28 / 58$ & $44 / 66$ & & $131 / 259$ \\
\hline Model 1 & 1.00 (Ref) & $0.96(0.50,1.85)$ & $1.08(0.55,2.13)$ & $1.53(0.80,2.92)$ & 0.054 & $1.20(0.94,1.53)$ \\
\hline Model 2 & 1.00 (Ref) & $0.90(0.46,1.76)$ & $1.12(0.55,2.24)$ & $1.50(0.76,2.98)$ & 0.056 & $1.20(0.93,1.56)$ \\
\hline \multicolumn{7}{|l|}{ ALT } \\
\hline Model 1 & 1.00 (Ref) & $0.96(0.50,1.84)$ & $1.28(0.67,2.43)$ & $1.22(0.61,2.45)$ & 0.361 & $1.10(0.87,1.40)$ \\
\hline Model 2 & 1.00 (Ref) & $0.91(0.46,1.78)$ & $1.28(0.66,2.48)$ & $1.16(0.55,2.44)$ & 0.430 & $1.09(0.85,1.41)$ \\
\hline \multicolumn{7}{|l|}{ AST } \\
\hline Model 1 & 1.00 (Ref) & $0.86(0.46,1.63)$ & $0.73(0.36,1.47)$ & $1.07(0.53,2.16)$ & 0.542 & $1.13(0.90,1.43)$ \\
\hline Model 2 & 1.00 (Ref) & $0.87(0.46,1.65)$ & $0.70(0.34,1.42)$ & $1.12(0.55,2.32)$ & 0.492 & $1.17(0.92,1.50)$ \\
\hline \multicolumn{7}{|l|}{ ALP } \\
\hline Model 1 & 1.00 (Ref) & $1.18(0.60,2.33)$ & $1.72(0.85,3.47)$ & $2.71(1.37,5.36)$ & 0.183 & $1.57(1.21,2.04)$ \\
\hline Model 2 & 1.00 (Ref) & $1.14(0.56,2.35)$ & $1.70(0.81,3.56)$ & $2.80(1.36,5.76)$ & 0.144 & $1.59(1.20,2.09)$ \\
\hline \multicolumn{7}{|l|}{ Bilirubin } \\
\hline Model 1 & 1.00 (Ref) & $0.74(0.41,1.34)$ & $0.74(0.38,1.42)$ & $1.05(0.55,1.99)$ & 0.768 & $1.01(0.80,1.27)$ \\
\hline Model 2 & 1.00 (Ref) & $0.69(0.37,1.28)$ & $0.71(0.35,1.44)$ & $1.18(0.59,2.35)$ & 0.474 & $1.06(0.83,1.36)$ \\
\hline
\end{tabular}

Model 1: matching factors: age at blood collection ( \pm 1 year), sex, study center, time of the day at blood collection ( \pm 3 hours), fasting status at blood collection ( $<3,3-6$, and $>6$ hours); among women, additionally by menopausal status (pre-, peri-, and postmenopausal), and hormone replacement therapy use at time of blood collection (yes/no).

Model 2: model $1+$ smoking status (never, former, current, missing), baseline (continuous, $\mathrm{g} / \mathrm{d}$ ) and lifetime alcohol intake pattern (never, former, lifetime drinker and drinker only at recruitment), body mass index (BMI, continuous $\mathrm{kg} / \mathrm{m}^{2}$ ), and physical activity (active, inactive, missing).

Cut-off values for sex-specific quartiles:

GGT- females $(<14,<=14-18 ;>=18-26,>=26 \mathrm{U} / \mathrm{L})$, males $(<18.5,>=18.5-26.5,>=26.5-41.5,>=41.5 \mathrm{U} / \mathrm{L})$

AST- females $(<15,>=15-18 ;>=18-21,>=21 \mathrm{U} / \mathrm{L})$, males $(<16,>=16-19 ;>=19-24,>=24 \mathrm{U} / \mathrm{L})$

ALP- females $(<51,>=51-64 ;>=64-77,>=77 \mathrm{U} / \mathrm{L})$, males $(<49,>=49-58 ;>=58-68,>=68 \mathrm{U} / \mathrm{L})$

ALT- females $(<11,>=11-15 ;>=15-20,>=20 \mathrm{U} / \mathrm{L})$, males $(<15,>=15-19 ;>=19-26,>=26 \mathrm{U} / \mathrm{L})$

Bilirubin- females $(<5.3,>=5.3-6.7 ;>=6.7-8.5,>=8.5 \mathrm{U} / \mathrm{L})$, males $(<6,>=6-7.75 ;>=7.75-10.2,>=10.2 \mathrm{U} / \mathrm{L})$

* $S D_{\log (G G T)}=0.66, S D_{\log (A L T)}=0.45, S D_{\log (A S T)}=0.30, S D_{\log (A L P)}=0.31, S D_{\log (\text { Bilirubin })}=0.42$

\subsection{Interactions and sensitivity analyses}

For HCC, an interaction was observed for WHR category with GGT category $(\mathrm{p}=0.013)$, but not for categories of BMI ( $\mathrm{p}=0.605)$, HSI $(\mathrm{p}=0.508), \mathrm{CRP}(\mathrm{p}=0.079)$, baseline alcohol intake $(\mathrm{p}=0.413)$ or intake pattern $(\mathrm{p}=0.717)$, sex $(\mathrm{p}=0.202)$, diabetes $(\mathrm{p}=0.366)$ or smoking status $(0.866)$. In analyses stratified by WHR category, the strongest HCC risk was observed in crude models for the highest WHR tertile (OR=5.91; 95\%CI:2.78-12.55). For ALP, an 
interaction was observed between the ALP quartiles and sex $(\mathrm{p}=0.0004)$. In the subgroup analyses, in men the highest ALP quartile exhibited a significantly higher risk of $\mathrm{HCC}(\mathrm{OR}=6.15 ; 95 \% \mathrm{CI}: 2.32-16.31)$, but this positive association was not significant for women in crude models ( $\mathrm{OR}=2.71 ; 95 \% \mathrm{CI}: 0.49-14.91)$. There was an interaction between AST category and alcohol drinking pattern $(\mathrm{p}=0.027)$. Due to low numbers of subjects, especially for controls in the former drinkers category, it was not possible to conduct subgroup analyses by alcohol intake pattern. No significant interactions existed for ALT.

No attenuation of the estimates was observed after excluding the first $2 / 4$ years of follow-up. After excluding individuals with positive hepatitis status, prevalent diabetes or suspected NAFLD, the significant outcomes remained. All liver functions biomarkers but bilirubin also remained statistically significant for HCC in the subgroup of individuals with suspected NAFLD (HSI>36) (not shown). Interestingly for GBTC, GGT reached the significance only for $\mathrm{HSI} \leq 36$ subgroup $(\mathrm{OR}=1.93 ; 95 \% \mathrm{CI}=1.12-3.33)$. When abnormal transaminases levels were excluded (ALT $<55 \mathrm{U} / \mathrm{L}$ and AST $<34 \mathrm{U} / \mathrm{L})$, the OR were: $1.85(95 \% \mathrm{CI}: 1.00-3.43)$ for GGT, $1.50(95 \% \mathrm{CI}: 0.82-2.74)$ for ALP and 1.24(95\%CI:0.73-2.10) for bilirubin, but remaining numbers of cases/controls were low, i.e. 55/98.

\section{DISCUSSION}

In this study, all of the measured liver enzymes (GGT, ALT, AST, ALP) and total bilirubin were shown to be positively associated with HCC risk. For IHBC, increases in the enzymes, but not bilirubin, were associated with higher risk. But for GBTC, which includes cancers of gallbladder and extra-hepatic bile ducts, only ALP showed a statistically significant association. Assessment of liver function markers can provide meaningful insight into the clinical condition of the liver, including cholestasis. For this reason, such markers are commonly measured in clinical practice. But, there is on-going discussion as to whether some, such as GGT, are simply risk markers or causally involved. GGT has been related to oxidative stress due to its role in glutathione (GSH) degradation, which may create a cancer-promotive environment in the surrounding tissues [24], and in the liver [25]. There is also evidence showing an elevation of GGT in obese or diabetic patients or those with liver steatosis [26]. These disorders are related to the metabolic syndrome which has itself also been associated with increased HCC risk [5]. A main limitation of our study is the lack of information on liver diseases, such as steatosis or cirrhosis. We attempted to address this in our analyses by controlling for some conditions that may be related to these syndromes (e.g. hepatitis infection status, alcohol intake, BMI, WHR, self-reported history of diabetes or cardiovascular disease, CRP level and calculated hepatic steatosis index). However, we did not observe appreciable confounding for these factors, except for WHR. This may suggest that abdominal obesity and obesity-associated chronic inflammation and oxidative stress [27], may in large part drive this association. 
Individually, liver function biomarkers lack specificity and their abnormal measures may be indicative of either hepatic [28] and/or extra-hepatic disorders, but also underlying cholestasis, biliary obstruction or bile duct inflammation $[7,29]$. Transaminases (AST and ALT), that we identified as positively associated with cancers located within the liver (HCC, IHBC), are mostly of hepatic origin, located in intracellular compartments and typically related to hepatic injury from either hepatitis infection, NAFLD, liver cirrhosis or other causes [29]. ALT is expressed mainly in the liver and is most specific indictor of liver injury [29]. ALP is produced in the membranes of cells lining bile ducts [28] and appears elevated in extrahepatic disease. The positive association of ALP with GBTC risk may be due to chronic inflammation in the bile ducts [29], which then affects liver function, but this requires further testing and assessment. In contrast, GGT is expressed on the cell surface and thus is released to the circulation quicker than the other enzymes in case of hepatic injury [24]. GGT is characterised by a high sensitivity but a low specificity to a particular disease of hepatobiliary tract, however in conjunction with ALP they may suggest chronic inflammation in the bile ducts of hepatic origin [29]. In our study, GGT showed the strongest association with HCC risk out of all the biomarkers assessed, consistent with previous observations on hepatitis infected subjects [14]. As for total bilirubin, although its elevated levels have been seen in hepatic failure in conjunction with other liver biomarkers [7], there is some evidence suggestive of an inverse association with colorectal, lung and breast cancer risk or mortality, likely due to its antioxidant properties [30-32] . In this study we observed a positive association with total bilirubin. The liver is involved in bilirubin metabolism, particularly its conjugation. Hence, it could be assumed that liver dysfunction may result in higher circulating bilirubin concentrations due to some underlying liver disease process [33]. It follows that observed HCC risk associations for bilirubin could then be positive. Indeed, abnormal high bilirubin levels ( $\geq 1.5 \mathrm{mg} / \mathrm{dL}$ ) have been shown in previous studies to be correlated with HCC aggressiveness [34]. Elevated bilirubin levels (1.5-9 mg/dL) with all other liver enzymes being normal or in the absence of liver disease are generally indicative of benign hereditary hyperbilirubinemia (Gilbert Syndrome). This is caused by a reduced activity of the liver enzyme uridine diphosphate-glucuronosyltransferase-1 [35]. In such a case, bilirubin is proposed to have cancer-protective properties, which is currently being investigated in ongoing epidemiological studies.

It is interesting that, as illustrated by the Loess curves, all of the biomarkers were higher in the HCC cases throughout the follow up period suggesting underlying physiological changes related to liver function long before clinical diagnosis. For example, elevation of liver enzymes and bilirubin has been observed in primary sclerosing cholangitis (PSC). PSC may lead to inflammatory damage of bile ducts both inside and outside of the liver, blocking the flow of bile, causing cholestasis and, finally, leading to biliary cirrhosis and liver failure [36]. Clinical guidelines also indicate that a ratio of AST/ALT above 2 may suggest alcoholic liver disease [7], and that GGT/ALP ratio above 2.5 may indicate alcoholic liver cirrhosis [37,28]. In our study having AST/ALT above 2 was associated with 
over five-fold higher HCC risk, and for subjects in the upper category for GGT/ALP (>2.5) the HCC risk was eight times higher than for the lower category. Although our observations are in line with what is known about the natural history of HCC development, it is interesting that the individual associations that we observed were maintained after adjustment for patterns of alcohol intake and levels of consumption.

A limitation of this study is a low number of cancer cases, which is a consequence of its prospective design wherein participants were recruited into the cohort prior to cancer development and followed over time, and the low incidence of the diseases studied. We also had no data on liver cirrhosis, NAFLD, NASH or steatosis that may partly mediate the observed associations. The possibility of reverse causation cannot be excluded, as is probably the case for any epidemiological study even those based on prospective designs However, we did carefully assess potential confounding and effect modification by metabolic markers that may be related to hepatic disorders (HSI, hepatitis, prevalent diabetes status, and numerous metabolic biomarkers), as well as level/patterns of alcohol consumption that may be related to development of liver cirrhosis. In sensitivity analyses, we also excluded the first two years of follow up and did not observe any change in the findings, suggesting that the observed alterations are early events. Lastly, all of the information and the biological samples were collected at baseline only and it is possible that dietary and lifestyle factors were modified during the follow up period affecting metabolic processes. The key strengths of our study include its prospective design and collection of detailed lifestyle information enabling adjustment for multiple confounders. We also evaluated the whole spectrum of enzymes and bilirubin, and had available prospectively measured hepatitis infection markers that could give a good picture of hepatic metabolic changes.

In conclusion, this study shows that all individually elevated liver enzymes and total bilirubin are good prediagnostic markers of cancers located within the liver (HCC, IHBC), but not in extra-hepatic compartments of hepatobiliary tract (GBTC). The study identified the most HCC-discriminant liver function biomarkers. A clinical validation study based on different patient cohorts with available markers for liver steatosis or fibrosis, i.e. in high risk individuals, would be valuable in order to test the clinical significance of this specific marker for population risk stratification and risk prediction modelling for early diagnosis. 


\section{ACKNOWLEDGEMENTS}

Financial support: This work was supported by the French National Cancer Institute (L'Institut National du Cancer; INCA) (grant number 2009-139; PI: M. Jenab). The coordination of EPIC is financially supported by the European Commission (DG-SANCO); and the International Agency for Research on Cancer. The national cohorts are supported by Danish Cancer Society (Denmark); Ligue Contre le Cancer; Institut Gustave Roussy; Mutuelle Générale de l'Education Nationale; and Institut National de la Santé et de la Recherche Médicale (INSERM) (France); Deutsche Krebshilfe, Deutsches Krebsforschungszentrum (DKFZ); and Federal Ministry of Education and Research (Germany); Stavros Niarchos Foundation; Hellenic Health Foundation; and Ministry of Health and Social Solidarity (Greece); Italian Association for Research on Cancer (AIRC); National Research Council; and AIRE-ONLUS Ragusa, AVIS Ragusa, Sicilian Government (Italy); Dutch Ministry of Public Health, Welfare and Sports (VWS); Netherlands Cancer Registry (NKR); LK Research Funds; Dutch Prevention Funds; Dutch ZON (Zorg Onderzoek Nederland); World Cancer Research Fund (WCRF); and Statistics Netherlands (the Netherlands); European Research Council (ERC) (grant number ERC-2009-AdG 232997) and Nordforsk; and Nordic Center of Excellence Programme on Food, Nutrition and Health (Norway); Health Research Fund (FIS); Regional Governments of Andalucía, Asturias, Basque Country, Murcia (No. 6236) and Navarra; and ISCIII RETIC (RD06/0020) and the Catalan Institute of Oncology. (Spain); Swedish Cancer Society; Swedish Scientific Council; and Regional Government of Skåne and Västerbotten (Sweden); Cancer Research UK; Medical Research Council; Stroke Association; British Heart Foundation; Department of Health; Food Standards Agency; and Wellcome Trust (UK).

Reagents for the hepatitis infection determinations were kindly provided by Abbott Diagnostics Division, Lyon, France. The funding sources had no influence on the design of the study; the collection, analysis, and interpretation of data; the writing of the report; or the decision to submit the paper for publication.

\section{Conflict of interests: None}




\section{REFERENCES}

1. IARC (2012) Estimated incidence, mortality and 5-year prevalence. http://globocan.iarc.fr/Pages/fact_sheets_cancer.aspx. Accessed 27 August 2014 2. Page AJ, Cosgrove DC, Philosophe B, Pawlik TM (2014) Hepatocellular carcinoma: diagnosis, management, and prognosis. Surgical oncology clinics of North America 23 (2):289-311. doi:10.1016/j.soc.2013.10.006

3. Gomaa AI, Khan SA, Toledano MB, Waked I, Taylor-Robinson SD (2008) Hepatocellular carcinoma: epidemiology, risk factors and pathogenesis. World journal of gastroenterology : WJG 14 (27):4300-4308

4. Michelotti GA, Machado MV, Diehl AM (2013) NAFLD, NASH and liver cancer. Nature reviews Gastroenterology \& hepatology 10 (11):656-665. doi:10.1038/nrgastro.2013.183 5. Jinjuvadia R, Patel S, Liangpunsakul S (2014) The association between metabolic syndrome and hepatocellular carcinoma: systemic review and meta-analysis. Journal of clinical gastroenterology 48 (2):172-177. doi:10.1097/MCG.0b013e3182a030c4

6. Augustine MM, Fong Y (2014) Epidemiology and risk factors of biliary tract and primary liver tumors. Surgical oncology clinics of North America 23 (2):171-188.

doi:10.1016/j.soc.2013.10.001

7. Giannini EG, Testa R, Savarino V (2005) Liver enzyme alteration: a guide for clinicians. CMAJ : Canadian Medical Association journal = journal de l'Association medicale canadienne 172 (3):367-379. doi:10.1503/cmaj.1040752

8. Kim CH, Park JY, Lee KU, Kim JH, Kim HK (2009) Association of serum gammaglutamyltransferase and alanine aminotransferase activities with risk of type 2 diabetes mellitus independent of fatty liver. Diabetes/metabolism research and reviews 25 (1):64-69. doi:10.1002/dmrr.890

9. Nannipieri M, Gonzales C, Baldi S, Posadas R, Williams K, Haffner SM, Stern MP, Ferrannini E (2005) Liver enzymes, the metabolic syndrome, and incident diabetes: the Mexico City diabetes study. Diabetes care 28 (7):1757-1762

10. Schlesinger S, Aleksandrova K, Pischon T, Jenab M, Fedirko V, Trepo E, Overvad K, Roswall N, Tjonneland A, Boutron-Ruault MC, Fagherazzi G, Racine A, Kaaks R, Grote VA, Boeing H, Trichopoulou A, Pantzalis M, Kritikou M, Mattiello A, Sieri S, Sacerdote C, Palli D, Tumino R, Peeters PH, Bueno-de-Mesquita HB, Weiderpass E, Quiros JR, Zamora-Ros R, Sanchez MJ, Arriola L, Ardanaz E, Tormo MJ, Nilsson P, Lindkvist B, Sund M, Rolandsson O, Khaw KT, Wareham N, Travis RC, Riboli E, Nothlings U (2013) Diabetes mellitus, insulin treatment, diabetes duration, and risk of biliary tract cancer and hepatocellular carcinoma in a European cohort. Annals of oncology : official journal of the European Society for Medical Oncology / ESMO 24 (9):2449-2455. doi:10.1093/annonc/mdt204 11. Lopez JB, Balasegaram M, Thambyrajah V, Timor J (1996) The value of liver function tests in hepatocellular carcinoma. The Malaysian journal of pathology 18 (2):95-99 12. Cha JM, Kim MH, Lee SK, Seo DW, Lee SS, Lee JH, Lee SG, Jang SJ (2006) Clinicopathological review of 61 patients with early bile duct cancer. Clin Oncol (R Coll Radiol) 18 (9):669-677

13. Kunutsor SK, Apekey TA, Van Hemelrijck M, Calori G, Perseghin G (2015) Gamma glutamyltransferase, alanine aminotransferase and risk of cancer: systematic review and metaanalysis. International journal of cancer Journal international du cancer 136 (5):1162-1170. doi:10.1002/ijc.29084

14. Hann HW, Wan S, Myers RE, Hann RS, Xing J, Chen B, Yang H (2012) Comprehensive analysis of common serum liver enzymes as prospective predictors of hepatocellular carcinoma in HBV patients. PloS one 7 (10):e47687. doi:10.1371/journal.pone.0047687 
15. Lin YJ, Lee MH, Yang HI, Jen CL, You SL, Wang LY, Lu SN, Liu J, Chen CJ (2013) Predictability of liver-related seromarkers for the risk of hepatocellular carcinoma in chronic hepatitis B patients. PloS one 8 (4):e61448. doi:10.1371/journal.pone.0061448 16. Wen CP, Lin J, Yang YC, Tsai MK, Tsao CK, Etzel C, Huang M, Hsu CY, Ye Y, Mishra L, Hawk E, Wu X (2012) Hepatocellular carcinoma risk prediction model for the general population: the predictive power of transaminases. Journal of the National Cancer Institute 104 (20):1599-1611. doi:10.1093/jnci/djs372

17. Van Hemelrijck M, Jassem W, Walldius G, Fentiman IS, Hammar N, Lambe M, Garmo H, Jungner I, Holmberg L (2011) Gamma-glutamyltransferase and risk of cancer in a cohort of 545,460 persons - the Swedish AMORIS study. Eur J Cancer 47 (13):2033-2041. doi:10.1016/j.ejca.2011.03.010

18. Riboli E, Hunt KJ, Slimani N, Ferrari P, Norat T, Fahey M, Charrondiere UR, Hemon B, Casagrande C, Vignat J, Overvad K, Tjonneland A, Clavel-Chapelon F, Thiebaut A, Wahrendorf J, Boeing H, Trichopoulos D, Trichopoulou A, Vineis P, Palli D, Bueno-DeMesquita HB, Peeters PH, Lund E, Engeset D, Gonzalez CA, Barricarte A, Berglund G, Hallmans G, Day NE, Key TJ, Kaaks R, Saracci R (2002) European Prospective Investigation into Cancer and Nutrition (EPIC): study populations and data collection. Public health nutrition 5 (6B):1113-1124. doi:10.1079/PHN2002394

19. Riboli E, Kaaks R (1997) The EPIC Project: rationale and study design. European Prospective Investigation into Cancer and Nutrition. Int J Epidemiol 26 Suppl 1:S6-14 20. Trichopoulos D, Bamia C, Lagiou P, Fedirko V, Trepo E, Jenab M, Pischon T, Nöthlings U (2011) Hepatocellular carcinoma risk factors and disease burden in a European cohort: A nested case-control study. Journal of the National Cancer Institute 103:1-10 21. Lee JH, Kim D, Kim HJ, Lee CH, Yang JI, Kim W, Kim YJ, Yoon JH, Cho SH, Sung MW, Lee HS (2010) Hepatic steatosis index: a simple screening tool reflecting nonalcoholic fatty liver disease. Digestive and liver disease : official journal of the Italian Society of Gastroenterology and the Italian Association for the Study of the Liver 42 (7):503-508. doi:10.1016/j.dld.2009.08.002

22. Choi JW (2003) Association between elevated serum hepatic enzyme activity and total body fat in obese humans. Annals of clinical and laboratory science 33 (3):257-264 23. Jang ES, Jeong SH, Hwang SH, Kim HY, Ahn SY, Lee J, Lee SH, Park YS, Hwang JH, Kim JW, Kim N, Lee DH (2012) Effects of coffee, smoking, and alcohol on liver function tests: a comprehensive cross-sectional study. BMC gastroenterology 12:145. doi:10.1186/1471-230X-12-145

24. Whitfield JB (2001) Gamma glutamyl transferase. Critical reviews in clinical laboratory sciences 38 (4):263-355. doi:10.1080/20014091084227

25. Zhao J, Zhao Y, Wang H, Gu X, Ji J, Gao C (2011) Association between metabolic abnormalities and HBV related hepatocelluar carcinoma in Chinese: a cross-sectional study. Nutrition journal 10:49. doi:10.1186/1475-2891-10-49

26. Jiang S, Jiang D, Tao Y (2013) Role of gamma-glutamyltransferase in cardiovascular diseases. Experimental and clinical cardiology 18 (1):53-56

27. Savini I, Catani MV, Evangelista D, Gasperi V, Avigliano L (2013) Obesity-associated oxidative stress: strategies finalized to improve redox state. International journal of molecular sciences 14 (5):10497-10538. doi:10.3390/ijms 140510497

28. Hall P, Cash J (2012) What is the real function of the liver 'function' tests? The Ulster medical journal $81(1): 30-36$

29. Aragon G, Younossi ZM (2010) When and how to evaluate mildly elevated liver enzymes in apparently healthy patients. Cleveland Clinic journal of medicine 77 (3):195-204.

doi:10.3949/ccjm.77a.09064 
30. Zucker SD, Horn PS, Sherman KE (2004) Serum bilirubin levels in the U.S. population: gender effect and inverse correlation with colorectal cancer. Hepatology 40 (4):827-835. doi:10.1002/hep.20407

31. Wen CP, Zhang F, Liang D, Wen C, Gu J, Skinner H, Chow WH, Ye Y, Pu X, Hildebrandt MA, Huang M, Chen CH, Hsiung CA, Tsai MK, Tsao CK, Lippman SM, Wu X (2015) The ability of bilirubin in identifying smokers with higher risk of lung cancer: a large cohort study in conjunction with global metabolomic profiling. Clinical cancer research : an official journal of the American Association for Cancer Research 21 (1):193-200. doi:10.1158/1078-0432.CCR-14-0748

32. Ching S, Ingram D, Hahnel R, Beilby J, Rossi E (2002) Serum levels of micronutrients, antioxidants and total antioxidant status predict risk of breast cancer in a case control study. The Journal of nutrition 132 (2):303-306

33. Erlinger S, Arias IM, Dhumeaux D (2014) Inherited disorders of bilirubin transport and conjugation: new insights into molecular mechanisms and consequences. Gastroenterology 146 (7):1625-1638. doi:10.1053/j.gastro.2014.03.047

34. Carr BI, Guerra V, Giannini EG, Farinati F, Ciccarese F, Ludovico Rapaccini G, Di

Marco M, Benvegnu L, Zoli M, Borzio F, Caturelli E, Chiaramonte M, Trevisani F (2014)

Association of abnormal plasma bilirubin with aggressive hepatocellular carcinoma

phenotype. Seminars in oncology 41 (2):252-258. doi:10.1053/j.seminoncol.2014.03.006

35. Kundur AR, Singh I, Bulmer AC (2015) Bilirubin, platelet activation and heart disease: a missing link to cardiovascular protection in Gilbert's syndrome? Atherosclerosis 239 (1):7384. doi:10.1016/j.atherosclerosis.2014.12.042

36. Mendes FD, Lindor KD (2004) Primary sclerosing cholangitis. Clinics in liver disease 8 (1):195-211. doi:10.1016/S1089-3261(03)00127-2

37. Botros M, Sikaris KA (2013) The De Ritis Ratio: The Test of Time. The Clinical biochemist Reviews / Australian Association of Clinical Biochemists 34 (3):117-130 


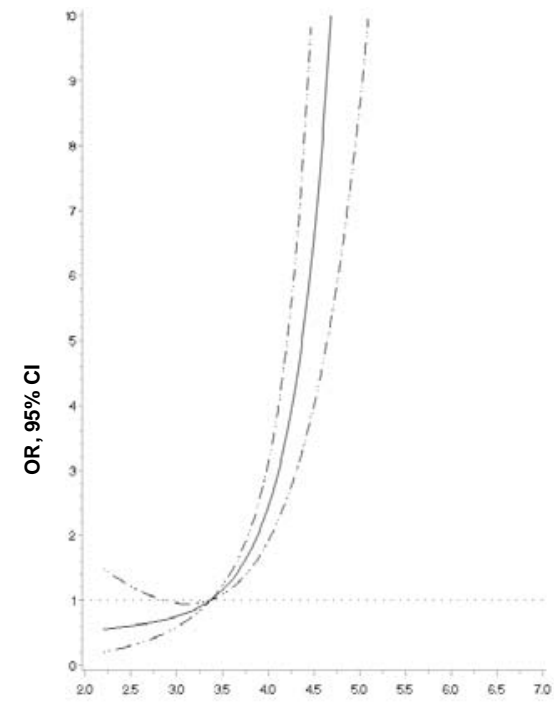

Log-transformed GGT (U/L) 


\section{Additional statistical analyses}

\section{Description of the study population and biomarker levels for different follow up times for HCC risk}

Comparisons of the baseline subject characteristics were done using the t-test for continuous variables and the chisquare test for categorical variables. Age-, sex-, fasting status-, hepatitis infection- and smoking-adjusted Spearman's partial correlation coefficients were used to assess the correlations between biomarkers studied (liver enzymes and bilirubin) and selected risk factors among controls. Differences in natural log-transformed biomarker levels according to different strata of variables of interest, stratified by sex, and adjusted for BMI, fasting status and country were assessed by generalized linear model (GLM). To visualize biomarker level over follow up time, Loess curves separate for cases and controls were presented for each enzyme, bilirubin and AFP by the time of follow up. For better visualization, the reference follow up time was assigned to the control subjects based on the follow up time of their corresponding cases.

\section{Additional analyzes- biomarker ratios, liver function score and hepatic steatosis index (HSI)}

The analyses for HCC and GBTC were conducted separately for men and women. Ratios of AST/ALT and GGT/ALP, used as supporting indicators of the source of liver disease, were calculated and categorised. The cut-off values for AST/ALT and GGT/ALP categories were 2 and 2.5, respectively, suggesting alcohol-related causes [24]. A liver function score (0-6) was constructed based on our data summarizing the number of abnormal values for five liver function tests $(\operatorname{ALT}>55 \mathrm{U} / \mathrm{L}, \mathrm{AST}>34 \mathrm{U} / \mathrm{L}$, GGT men $>64 \mathrm{U} / \mathrm{L}$, GGT women $>36 \mathrm{U} / \mathrm{L}, \mathrm{ALP}>150 \mathrm{U} / \mathrm{L}$, bilirubin $>20.5 \mu \mathrm{mol} / \mathrm{L}$ and albumin $<34 \mathrm{~g} / \mathrm{L}$; cut-points based directly on assay specifications). For biomarker level above the clinical threshold a mark of 1 was assigned, and 0 if the biomarker level was below this threshold. Two categories were constructed based on this score: a reference category with none biomarkers elevated (score $=0)$ and a category of one and more elevated biomarkers (score 1-6), suggesting possible impaired liver function. Hepatic steatosis index (HSI) score was calculated based on the threshold $(\leq 36>)$, which is the cut-off value for assessment of possible NAFLD. The association of liver function and HSI score and the ratios categories with risk of HCC, IHBC and GBTC was also calculated using conditional logistic regression models. Due to very low numbers of control participants with enzyme levels above the clinical threshold we were unable to obtain estimates for dichotomised variable of under- above- this threshold of each biomarker.

\section{Discriminatory accuracy of the models- ROC curves}

Receiver operating characteristics (ROC) curves were constructed for each individual biomarker of interest and their combinations. In order to reduce bias, the dataset was randomly split into training $(60 \%, 70$ cases and 141 controls) and testing $(40 \%, 51$ cases, 101 controls) components. Using the training component, the best discriminatory model between cases and controls based on liver function biomarkers was selected according to the area under the ROC curves (AUROC) using a stepwise selection method. In exploratory analyses we further applied the selected models 
by time of follow up (cut-offs 1 and 2 years) and in hepatitis free subjects (to exclude potential effect of hepatitis infection on liver enzyme levels). Due to sample size limitation of the training and testing subgroups, the exploratory analyses were conducted on the total number of cases and controls. The models were considered ranked as excellent (AUROC greater than 90\%), good (AUROC above 80\%), fair (AUROC below 80\%), and poor (AUROC less than 70\%).

\section{Supplementary Results}

\section{Description of the study population}

More than $70 \%$ of HCC cases had at least one abnormal liver function test whereas the percentages for IHBC and GBTC cases were $46 \%$ and $15 \%$, respectively. Observed correlations between liver biomarkers, dietary intakes and anthropometric measures among controls are presented in Supplementary Table 2. Liver enzymes correlated with each other, CRP and albumin, but also body fatness measures and alcohol intake. Serum liver enzyme levels according to different strata of variables of interest are presented in Supplementary tables 3-6.

\section{Biomarker levels for different follow-up times for HCC}

As assessed by visual inspection of Loess curves, the levels of all standardised enzymes were lower for HCC controls than the cases for different follow-up periods of their cases (Supplementary Fig. 1). For GGT and AST the case-control difference became more pronounced closer to the time of diagnosis, especially within 2.5 years. Similar but less clear pattern was seen for bilirubin and ALT, but not for AFP, for which the levels were higher only within the 2.5 years prior to $\mathrm{HCC}$ diagnosis.

\section{Additional analyses}

Adjustment for self-reported history of gallstones did not alter the findings. For both HCC and GBTC, findings were similar in men and women (Supplementary Tables 7 and 8). The estimates for the liver function score based on abnormal values of liver enzymes, bilirubin and albumin, as well as for enzyme ratio categories (AST/ALT and GGT/ALP) and HSI, in relation to HCC, IHBC and GBTC are presented in Supplementary Table 9. Significantly positive associations for subjects with at least one abnormal liver function test in multivariable model were observed for HCC and IHBC and for the ratios for HCC. No significant associations were observed for HSI in multivariable adjusted models.

\section{Discriminatory accuracy of the models- ROC curves}

ROC was used to illustrate changes in model discriminatory accuracy by comparing AUROC among individual biomarkers and their combinations. For individual enzymes in relation to HCC, AUROC was the highest $82 \%$ for GGT, AST and ALP followed by AFP (80\%), ALT (75\%) and bilirubin (73\%). For the combination of biomarkers after stepwise selection the best performance was observed for GGT, AST and ALP (AUROC=0.88, 95\%CI:0.820.94), suggesting that these are most HCC-specific biomarkers. Addition of ALT and/or bilirubin did not further 
improve the model. Excellent predictive accuracy was observed within the $1^{\text {st }}$ year of follow up. In this subset, the discriminatory accuracy based on the model including the three enzymes was $93 \%$ (AUROC $=0.93,95 \% \mathrm{CI}$ :0.851.00). The exclusion of subjects diagnosed within 1or 2 years of recruitment had lower, but still good discriminatory power ( 82 and $83 \%$, respectively). In subgroup analyses by HSI, discriminatory power for the combination of the 3 biomarkers was 79 and $86 \%$ for those with unlikely and suspected NAFLD, respectively, indicating its good performance in both healthy and higher HCC risk individuals. In hepatitis free individuals, as based on the full complement of cases and matched controls, the accuracy of this model showed a fair performance; model based on GGT, AST and ALP differentiated cases from controls with 78\% accuracy. The prediction models performed only fair for IHBC and poor for GBTC for which weaker or no associations were observed.

A biomarker based on the sum of these biomarkers (GGT, ALT and AST) increased HCC risk by 90\% (34-134\%), even if hepatic, diabetic or participants with suspected NAFLD were only considered. Only exclusion of obese participants attenuated the significance $(\mathrm{OR}=4.17$; 95\%CI: $0.51-34.20)$. In subset of obese subjects similar risk increase to the whole cohort was observed $(\mathrm{OR}=1.93 ; 95 \% \mathrm{CI}: 1.41-2.63)$. This biomarker could be potentially used to identify which obese individuals should be referred for screening of HCC. 


\section{Supplementary tables}

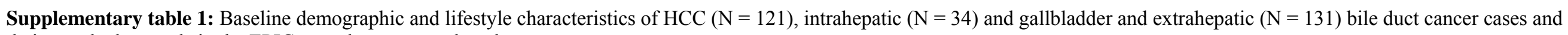
their matched controls in the EPIC nested case-control study.

\begin{tabular}{|c|c|c|c|c|c|c|c|c|c|c|c|c|}
\hline \multirow{2}{*}{ Characteristics } & \multicolumn{4}{|c|}{ Hepatocellular Carcinoma (HCC) } & \multicolumn{4}{|c|}{$\begin{array}{l}\text { Tumours of the Intrahepatic Bile Ducts } \\
\text { (IHBC) }\end{array}$} & \multicolumn{4}{|c|}{$\begin{array}{l}\text { Tumours of the Gallbladder and } \\
\text { Extrahepatic Bile Ducts (GBTC) }\end{array}$} \\
\hline & \multicolumn{2}{|c|}{ Cases $(\mathrm{N}=121)$} & \multicolumn{2}{|c|}{$\begin{array}{l}\text { Matched controls } \\
\quad(\mathrm{N}=242)\end{array}$} & \multicolumn{2}{|c|}{ Cases $(N=34)$} & \multicolumn{2}{|c|}{$\begin{array}{l}\text { Matched controls } \\
\quad(\mathbf{N}=67)\end{array}$} & \multicolumn{2}{|c|}{ Cases $(\mathrm{N}=131)$} & \multicolumn{2}{|c|}{$\begin{array}{l}\text { Matched controls } \\
(\mathrm{N}=259)\end{array}$} \\
\hline Never smoker & 33 & 27.3 & 104 & 43.0 & 16 & 47.1 & 29 & 43.3 & 57 & 43.5 & 123 & 47.5 \\
\hline Former smoker & 39 & 32.2 & 91 & 37.6 & 9 & 26.5 & 14 & 20.9 & 38 & 29.0 & 81 & 31.3 \\
\hline Current smoker & 47 & 38.8 & 46 & 19.0 & 8 & 23.5 & 20 & 29.9 & 35 & 26.7 & 53 & 20.5 \\
\hline \multicolumn{13}{|l|}{ No. with gallstones $(\mathrm{N}, \%)^{\mathrm{b}}$} \\
\hline No & 74 & 61.2 & 154 & 63.6 & 17 & 50 & 42 & 62.7 & 69 & 52.7 & 148 & 57.1 \\
\hline Yes & 15 & 12.4 & 24 & 9.9 & 7 & 20.59 & 3 & 4.5 & 13 & 9.9 & 13 & 5.0 \\
\hline \multicolumn{13}{|l|}{ Total physical activity $(\mathrm{N}, \%)^{\mathrm{c}}$} \\
\hline Inactive & 11 & 9.1 & 33 & 13.6 & 5 & 14.7 & 6 & 9.0 & 20 & 15.3 & 37 & 14.3 \\
\hline Moderately inactive & 37 & 30.6 & 72 & 29.8 & 11 & 32.4 & 21 & 31.3 & 43 & 32.8 & 83 & 32.0 \\
\hline Moderately active & 68 & 56.2 & 129 & 53.3 & 15 & 44.1 & 36 & 53.7 & 62 & 47.3 & 127 & 49.0 \\
\hline None & 30 & 24.8 & 22 & 9.1 & 7 & 20.6 & 11 & 16.4 & 21 & 16.0 & 34 & 13.1 \\
\hline $0.1-6$ & 33 & 27.3 & 77 & 31.8 & 10 & 29.4 & 24 & 35.8 & 45 & 34.4 & 86 & 33.2 \\
\hline $6.1-12$ & 12 & 9.9 & 43 & 17.8 & 3 & 8.8 & 3 & 4.5 & 23 & 17.6 & 33 & 12.7 \\
\hline $12.1-24$ & 15 & 12.4 & 49 & 20.2 & 6 & 17.7 & 14 & 20.9 & 20 & 15.3 & 62 & 23.9 \\
\hline $24.1-60$ & 19 & 15.7 & 40 & 16.5 & 8 & 23.5 & 13 & 19.4 & 14 & 10.7 & 33 & 12.7 \\
\hline$>60$ & 12 & 9.9 & 11 & 4.5 & 0 & 0 & 2 & 3.0 & 8 & 6.1 & 11 & 4.2 \\
\hline \multicolumn{13}{|l|}{ Drinking history $(\mathrm{N}, \%)$} \\
\hline Never drinker & 12 & 9.9 & 19 & 7.9 & 6 & 17.6 & 10 & 14.9 & 12 & 9.2 & 23 & 8.9 \\
\hline Former drinker & 18 & 14.9 & 3 & 1.2 & 1 & 2.9 & 1 & 1.5 & 8 & 6.1 & 9 & 3.5 \\
\hline Drinker at recruitment & 21 & 17.4 & 52 & 21.5 & 5 & 14.7 & 10 & 14.9 & 36 & 27.5 & 78 & 30.1 \\
\hline Lifetime drinker & 70 & 57.9 & 168 & 69.4 & 22 & 64.7 & 46 & 68.7 & 75 & 57.3 & 149 & 57.5 \\
\hline Hepatitis B positive $(\mathrm{N}, \%)$ & 16 & 13.2 & 5 & 2.1 & 0 & 0 & 3 & 4.5 & 3 & 2.3 & 11 & 4.3 \\
\hline Hepatitis $\mathrm{C}$ positive $(\mathrm{N}, \%)$ & 24 & 19.8 & 6 & 2.5 & 0 & 0 & 1 & 1.5 & 3 & 2.3 & 3 & 1.2 \\
\hline
\end{tabular}


Missing values were not excluded from percentage calculations, thus the sum of percents across sub-groups may not add up to $100 \%$.

Categorical variables are presented as numbers and percentages.

Continuous variables are presented as mean and standard deviations, except for liver function tests that are presented as medianand5, 95 \%).

${ }^{a}$ Number of cases and controls with missing variable value: $\mathrm{HCC}=3, \mathrm{IHBC}=5$, and $\mathrm{EBD}=3$.

${ }^{\mathrm{b}}$ Number of cases and controls with missing variable value: $\mathrm{HCC}=96, \mathrm{IHBC}=32$, and $\mathrm{EBD}=147$.

${ }^{\mathrm{c}}$ Total physical activity categories were sex-specific. Number of cases and controls with missing variable value: $\mathrm{HCC}=13, \mathrm{IHBC}=7$, and $\mathrm{EBD}=18$. 
Supplementary table 2: Spearman correlations for liver biomarkers and selected potential confounders in the controls $(\mathrm{n}=722)$.

\begin{tabular}{|c|c|c|c|c|c|c|c|c|c|c|c|c|}
\hline & $\begin{array}{l}\text { GGT } \\
(\mathrm{U} / \mathrm{L})\end{array}$ & $\begin{array}{l}\text { AST } \\
(\mathrm{U} / \mathrm{L})\end{array}$ & $\begin{array}{l}\text { ALT } \\
(\mathrm{U} / \mathrm{L})\end{array}$ & $\begin{array}{l}\text { ALP } \\
(\mathrm{U} / \mathrm{L})\end{array}$ & $\begin{array}{l}\text { Bilirubi } \\
\mathrm{n} \\
(\mathrm{U} / \mathrm{L})\end{array}$ & $\begin{array}{l}\text { Albumin } \\
(\mathrm{g} / \mathrm{L})\end{array}$ & $\begin{array}{l}\text { CRP } \\
(\mathrm{mg} / \mathrm{dL})\end{array}$ & $\begin{array}{l}\text { BMI } \\
(\mathrm{kg} / \mathrm{m} 2)\end{array}$ & WHR & $\begin{array}{l}\text { Alcohol } \\
\text { intake at } \\
\text { recruitment } \\
(\mathrm{g} / \mathrm{d})\end{array}$ & $\begin{array}{l}\text { Coffee } \\
\text { intake } \\
(\mathrm{g} / \mathrm{d})\end{array}$ & $\begin{array}{l}\text { Energy } \\
\text { intake } \\
(\mathrm{kcal} / \mathrm{d})\end{array}$ \\
\hline GGT (U/L), $\rho$ & 1 & & & & & & & & & & & \\
\hline \multicolumn{13}{|l|}{$\mathrm{p}$} \\
\hline $\mathrm{AST}(\mathrm{U} / \mathrm{L}), \rho$ & 0.43 & 1 & & & & & & & & & & \\
\hline $\mathrm{p}$ & $<.0001$ & & & & & & & & & & & \\
\hline $\operatorname{ALT}(\mathrm{U} / \mathrm{L}), \rho$ & 0.58 & 0.69 & 1 & & & & & & & & & \\
\hline $\mathrm{p}$ & $<.0001$ & $<.0001$ & & & & & & & & & & \\
\hline $\operatorname{ALP}(\mathrm{U} / \mathrm{L}), \rho$ & 0.28 & 0.16 & 0.29 & 1 & & & & & & & & \\
\hline $\mathrm{p}$ & $<.0001$ & 0.000 & $<.0001$ & & & & & & & & & \\
\hline Bilirubin $(g / L), \rho$ & 0.08 & 0.03 & 0.07 & -0.03 & 1 & & & & & & & \\
\hline $\mathrm{p}$ & 0.051 & 0.427 & 0.095 & 0.444 & & & & & & & & \\
\hline Albumin $(g / L), \rho$ & 0.13 & 0.17 & 0.17 & 0.08 & 0.17 & 1 & & & & & & \\
\hline $\mathrm{p}$ & 0.002 & $<.0001$ & $<.0001$ & 0.045 & $<.0001$ & & & & & & & \\
\hline $\mathrm{CRP}(\mathrm{mg} / \mathrm{dL}), \rho$ & 0.21 & 0.11 & 0.18 & 0.27 & -0.11 & -0.04 & 1 & & & & & \\
\hline $\mathrm{p}$ & $<.0001$ & 0.009 & $<.0001$ & $<.0001$ & 0.011 & 0.310 & & & & & & \\
\hline BMI $\left(\mathrm{kg} / \mathrm{m}^{2}\right), \rho$ & 0.16 & 0.04 & 0.28 & 0.18 & -0.08 & 0.00 & 0.26 & 1 & & & & \\
\hline $\mathrm{p}$ & $<.0001$ & 0.317 & $<.0001$ & $<.0001$ & 0.064 & 0.935 & $<.0001$ & & & & & \\
\hline WHR, $\rho$ & 0.21 & 0.08 & 0.27 & 0.17 & -0.03 & 0.06 & 0.24 & 0.50 & 1 & & & \\
\hline $\mathrm{p}$ & $<.0001$ & 0.057 & $<.0001$ & $<.0001$ & 0.452 & 0.169 & $<.0001$ & $<.0001$ & & & & \\
\hline Alcohol intake at recruitment $(\mathrm{g} / \mathrm{d}), \rho$ & 0.24 & 0.17 & 0.07 & -0.06 & 0.16 & 0.09 & -0.01 & -0.07 & -0.03 & 1 & & \\
\hline $\mathrm{p}$ & $<.0001$ & $<.0001$ & 0.112 & 0.185 & $<.0001$ & 0.029 & 0.820 & 0.111 & 0.456 & & & \\
\hline Coffee intake $(\mathrm{g} / \mathrm{d}), \rho$ & 0.05 & 0.00 & -0.03 & -0.02 & -0.08 & 0.05 & -0.03 & -0.07 & -0.04 & 0.11 & 1 & \\
\hline $\mathrm{p}$ & 0.240 & 0.954 & 0.412 & 0.605 & 0.060 & 0.220 & 0.454 & 0.099 & 0.322 & 0.006 & & \\
\hline Energy intake $(\mathrm{kcal} / \mathrm{d}), \rho$ & 0.01 & 0.02 & 0.01 & -0.01 & 0.00 & -0.16 & -0.07 & -0.02 & -0.06 & 0.20 & 0.08 & 1 \\
\hline $\mathrm{p}$ & 0.726 & 0.670 & 0.789 & 0.729 & 0.935 & 0.000 & 0.105 & 0.678 & 0.169 & $<.0001$ & 0.061 & \\
\hline
\end{tabular}

Spearman correlations $(\rho)$ were conducted after adjustment for sex, age, fasting status, prevalent hepatitis infection and cigarette smoking. 
Supplementary table 3: Serum gamma-glutamyltransferase (GGT) concentrations (IU/L) according to categories of various predictor variables among controls in the EPIC nested case-control study, 1992-2004 (men, $\mathrm{n}=410$ and women, $\mathrm{n}=312$ ).

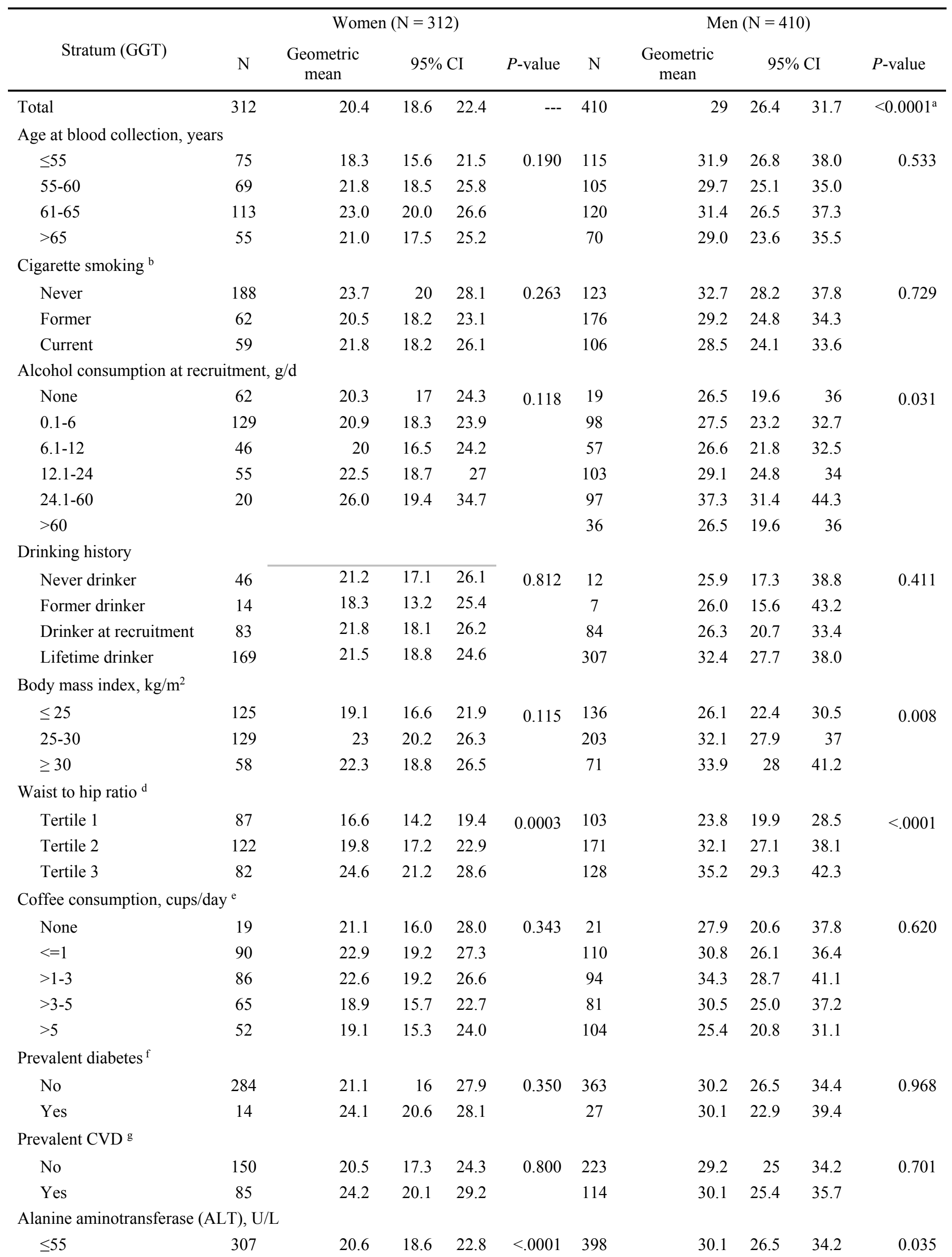


Aspartate aminotransferase (AST), U/L

$$
\begin{array}{cc}
\leq 34 & 303 \\
>34 & 9
\end{array}
$$

C-reactive protein (CRP), $\mathrm{mg} / \mathrm{L}$

$\begin{array}{lc}\leq 3 & 236 \\ >3 & 76\end{array}$

Hepatitis B infection

$\begin{array}{lc}\text { No } & 303 \\ \text { Yes } & 9\end{array}$

\begin{tabular}{|c|c|c|c|c|c|c|c|c|c|c|}
\hline No & 296 & 21.2 & 19.1 & 23.5 & 0.640 & 390 & 30.3 & 26.6 & 34.5 & 0.788 \\
\hline Yes & 16 & 19.7 & 14.3 & 27.1 & & 19 & 31.6 & 22.6 & 44.2 & \\
\hline
\end{tabular}

Hepatitis C infection

$\begin{array}{lc}\text { No } & 304 \\ \text { Yes } & 8\end{array}$

Hepatitis B or C infection ${ }^{\mathrm{h}}$

a $P$-value for comparison of $\ln (\mathrm{GGT})$ values between men and women, adjusted for fasting status, BMI and country

b Missing $\mathrm{N}=8$

c Missing $\mathrm{N}=164$

d Missing $N=29$ (women=21, men=8). Sex-specific tertiles (men: $\leq 0.92,0.92-0.97, \geq 0.97$; women: $\leq 0.77,0.77-0.84, \geq 0.84$ ).

e Based on the assumption that 1 cup $=150 \mathrm{~mL}$;

f Self-reported; missing $\mathrm{N}=34$

g Self-reported; missing $\mathrm{N}=150$

$\mathrm{h}$ The numbers of hepatitis B and C infected do not add up because one person had both, hepatitis B and C infections. 
Supplementary table 4: Serum alanine aminotransferase (ALT) concentrations (IU/L) according to categories of various predictor variables among controls in the EPIC nested case-control study, 1992-2004 (men, $\mathrm{n}=410$ and women, $\mathrm{n}=312$ ).

\begin{tabular}{|c|c|c|c|c|c|c|c|c|c|c|}
\hline \multirow[b]{3}{*}{ Total } & \multicolumn{5}{|c|}{ Women $(\mathrm{N}=312)$} & \multicolumn{5}{|c|}{$\operatorname{Men}(\mathrm{N}=410)$} \\
\hline & \multirow{2}{*}{$\frac{\mathrm{N}}{312}$} & \multirow{2}{*}{$\begin{array}{c}\begin{array}{c}\text { Geometric } \\
\text { mean }\end{array} \\
15.1\end{array}$} & \multicolumn{2}{|c|}{$95 \% \mathrm{CI}$} & \multirow{2}{*}{$\begin{array}{l}P \text {-value } \\
---\end{array}$} & \multirow{2}{*}{$\frac{\mathrm{N}}{410}$} & \multirow{2}{*}{$\begin{array}{c}\begin{array}{c}\text { Geometric } \\
\text { mean }\end{array} \\
19.1\end{array}$} & \multicolumn{2}{|c|}{$95 \% \mathrm{CI}$} & \multirow{2}{*}{$\begin{array}{c}P \text {-value } \\
<0.0001^{\mathrm{a}}\end{array}$} \\
\hline & & & 14.1 & 16.1 & & & & 17.9 & 20.3 & \\
\hline \multicolumn{11}{|c|}{ Age at blood collection, years } \\
\hline$\leq 55$ & 75 & 14.5 & 12.9 & 16.4 & \multirow[t]{4}{*}{0.5463} & 115 & 20.8 & 18.4 & 23.5 & \multirow[t]{4}{*}{0.0004} \\
\hline $55-60$ & 69 & 16.7 & 14.8 & 19.0 & & 105 & 20.4 & 18.1 & 22.9 & \\
\hline $61-65$ & 113 & 16.3 & 14.7 & 18.1 & & 120 & 19.6 & 17.4 & 22.1 & \\
\hline$>65$ & 55 & 14.2 & 12.4 & 16.3 & & 70 & 15.5 & 13.4 & 17.9 & \\
\hline \multicolumn{11}{|l|}{ Cigarette smoking ${ }^{b}$} \\
\hline Never & 188 & 17.4 & 15.4 & 19.7 & \multirow[t]{3}{*}{0.013} & 123 & 19.5 & 17.6 & 21.5 & \multirow[t]{3}{*}{0.021} \\
\hline Former & 62 & 14.9 & 13.7 & 16.3 & & 176 & 20.6 & 18.4 & 23.0 & \\
\hline Current & 59 & 13.8 & 12.1 & 15.8 & & 106 & 17.5 & 15.6 & 19.6 & \\
\hline \multicolumn{11}{|c|}{ Alcohol consumption at recruitment, $\mathrm{g} / \mathrm{d}$} \\
\hline None & 62 & 20.3 & 17 & 24.3 & \multirow[t]{6}{*}{0.118} & 19 & 26.5 & 19.6 & 36 & \multirow[t]{6}{*}{0.031} \\
\hline $0.1-6$ & 129 & 20.9 & 18.3 & 23.9 & & 98 & 27.5 & 23.2 & 32.7 & \\
\hline $6.1-12$ & 46 & 20 & 16.5 & 24.2 & & 57 & 26.6 & 21.8 & 32.5 & \\
\hline $12.1-24$ & 55 & 22.5 & 18.7 & 27 & & 103 & 29.1 & 24.8 & 34 & \\
\hline $24.1-60$ & 20 & 26.0 & 19.4 & 34.7 & & 97 & 37.3 & 31.4 & 44.3 & \\
\hline$>60$ & & & & & & 36 & 26.5 & 19.6 & 36 & \\
\hline \multicolumn{11}{|l|}{ Drinking history } \\
\hline Never drinker & 46 & 21.2 & 17.1 & 26.1 & 0.812 & 12 & 25.9 & 17.3 & 38.8 & 0.411 \\
\hline Former drinker & 14 & 18.3 & 13.2 & 25.4 & & 7 & 26.0 & 15.6 & 43.2 & \\
\hline Drinker at recruitment & 83 & 21.8 & 18.1 & 26.2 & & 84 & 26.3 & 20.7 & 33.4 & \\
\hline Lifetime drinker & 169 & 21.5 & 18.8 & 24.6 & & 307 & 32.4 & 27.7 & 38.0 & \\
\hline Body mass index, $\mathrm{kg} / \mathrm{m} 2$ & & & & & & & & & & \\
\hline$\leq 25$ & 125 & 13.1 & 11.9 & 14.5 & $<.0001$ & 136 & 16.1 & 14.5 & 18.0 & $<.0001$ \\
\hline $25-30$ & 129 & 16.7 & 15.2 & 18.4 & & 203 & 19.9 & 18.1 & 22.0 & \\
\hline$\geq 30$ & 58 & 17.7 & 15.6 & 20.0 & & 71 & 23.4 & 20.5 & 26.8 & \\
\hline Waist to hip ratio $d$ & & & & & & & & & & \\
\hline Tertile 1 & 87 & 14.5 & 12.9 & 16.2 & 0.0016 & 103 & 23.8 & 19.9 & 28.5 & $<.0001$ \\
\hline Tertile 2 & 122 & 15.7 & 14.1 & 17.4 & & 171 & 32.1 & 27.1 & 38.1 & \\
\hline Tertile 3 & 82 & 17.1 & 15.3 & 19.1 & & 128 & 35.2 & 29.3 & 42.3 & \\
\hline Coffee consumption, cups/ & & & & & & & & & & \\
\hline None & 19 & 16.0 & 13.1 & 19.7 & 0.3729 & 21 & 21.8 & 17.7 & 26.9 & 0.0933 \\
\hline$<=1$ & 111 & 15.8 & 13.9 & 18.0 & & 144 & 19.2 & 17.1 & 21.5 & \\
\hline$>1-3$ & 68 & 15.3 & 13.6 & 17.3 & & 66 & 19.9 & 17.6 & 22.5 & \\
\hline$>3-5$ & 114 & 14.7 & 12.8 & 16.8 & & 179 & 19.1 & 16.7 & 21.9 & \\
\hline$>5$ & 52 & 14.6 & 12.4 & 17.2 & & 104 & 17.4 & 15.2 & 20.0 & \\
\hline Prevalent diabetes $\mathrm{f}$ & & & & & & & & & & \\
\hline No & 284 & 15.1 & 13.9 & 16.3 & 0.972 & 363 & 19.0 & 17.4 & 20.8 & 0.284 \\
\hline Yes & 14 & 15.2 & 11.9 & 19.3 & & 27 & 20.9 & 17.4 & 25.1 & \\
\hline Prevalent CVD g & & & & & & & & & & \\
\hline No & 150 & 15.2 & 13.4 & 17.1 & 0.071 & 223 & 18.8 & 16.9 & 20.9 & 0.563 \\
\hline Yes & 85 & 17.1 & 15.0 & 19.6 & & 114 & 19.4 & 17.3 & 21.8 & \\
\hline Gamma glutamyltransferas & GT), & & & & & & & & & \\
\hline$\leq 36 / 64$ & 247 & 13.9 & 12.9 & 14.9 & $<.0001$ & 228 & 16.1 & 14.8 & 17.6 & $<.0001$ \\
\hline
\end{tabular}


$>36 / 64$
C-reactive protein (CRP), mg/L

$\leq 3$

$>3$

236

$\begin{array}{lll}21.7 & 19.4 & 24.2\end{array}$

182

$24.0 \quad 21.9 \quad 26.3$

Hepatitis B infection

$\begin{array}{lrrrrrrrrrr}\text { No } & 303 & 15.2 & 14.1 & 16.5 & 0.573 & 395 & 19.1 & 17.5 & 20.9 & 0.162 \\ \text { Yes } & 9 & 16.6 & 12.2 & 22.6 & & 14 & 22.9 & 17.6 & 29.7 & \\ \text { Hepatitis C infection } & & & & & & & & & & \\ \text { No } & 304 & 21.1 & 19 & 23.5 & 0.970 & 405 & 30.5 & 26.8 & 34.6 & 0.195 \\ \text { Yes } & 8 & 21 & 13.6 & 32.5 & & 5 & 20.7 & 11.5 & 37.5\end{array}$

Hepatitis B or C infection ${ }^{\mathrm{h}}$

No

296

15.2

$14.1 \quad 16.4$

$0.606 \quad 390$

$\begin{array}{lll}19.1 & 17.5 \quad 20.9\end{array}$

0.275

Yes

$\begin{array}{lll}16.2 & 12.8 \quad 20.4\end{array}$

19

$21.6 \quad 17.2 \quad 27.1$

a $P$-value for comparison of $\ln (\mathrm{ALT})$ values between men and women, adjusted for fasting status, BMI and country

b Missing $\mathrm{N}=8$

c Missing $\mathrm{N}=164$

d Missing $N=29$ (women=21, men=8). Sex-specific tertiles (men: $\leq 0.92,0.92-0.97, \geq 0.97$; women: $\leq 0.77,0.77-0.84$, $\geq 0.84$ ).

e Based on the assumption that 1 cup $=150 \mathrm{~mL}$;

f Self-reported; missing $\mathrm{N}=34$

g Self-reported; missing $\mathrm{N}=150$

$\mathrm{h}$ The numbers of hepatitis B and C infected do not add up because one person had both, hepatitis B and C infections. 
Supplementary table 5: Serum aspartate aminotransferase (AST) concentrations (IU/L) according to categories of various predictor variables among controls in the EPIC nested case-control study, 1992-2004 (men, n= 410 and women, $\mathrm{n}=312$ ).

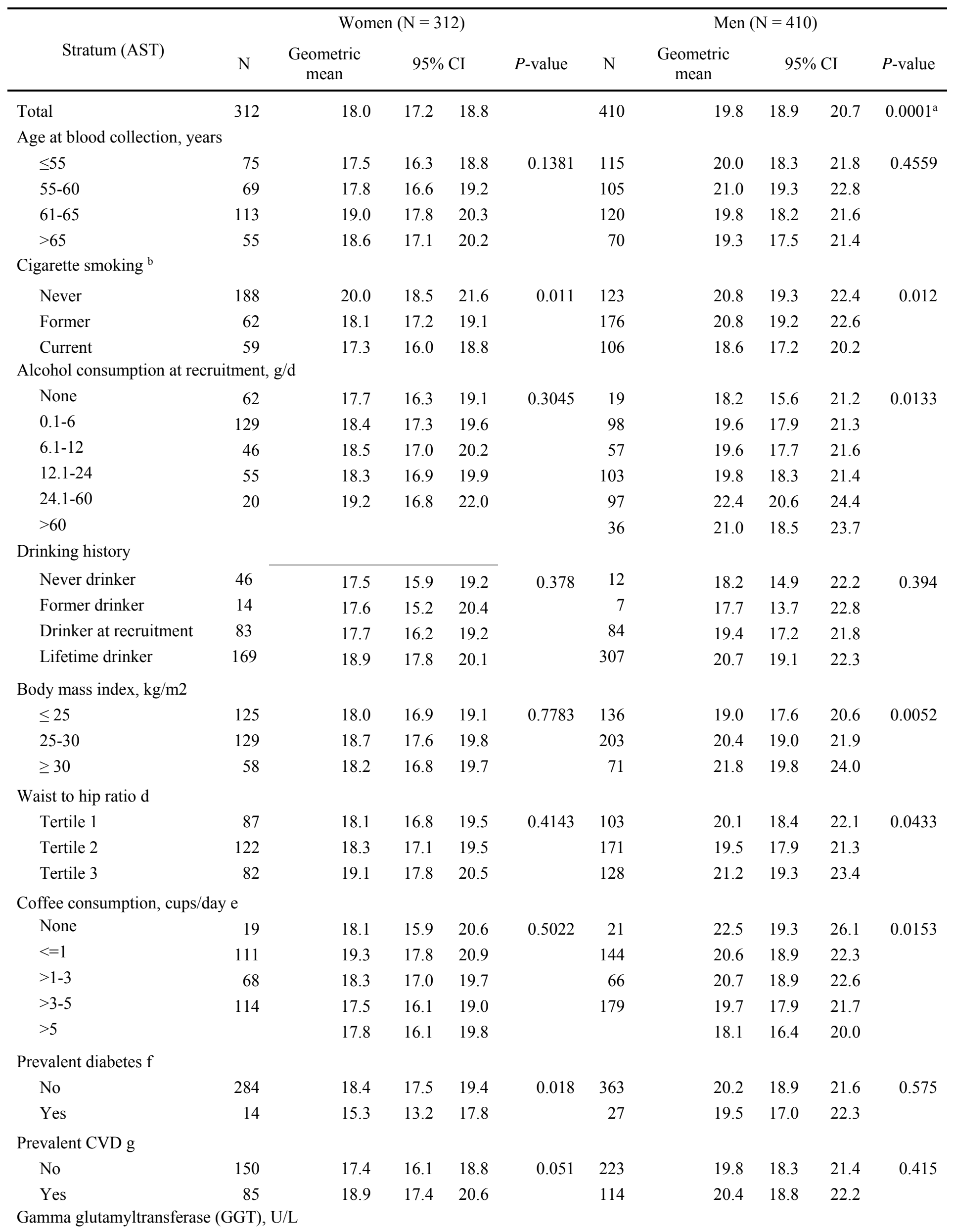




$\begin{array}{lrrrrrrrrrr}\leq 36 / 64 & 247 & 17.3 & 16.5 & 18.1 & <.0001 & 228 & 18.2 & 17.1 & 19.4 & <.0001 \\ >36 / 64 & 65 & 22.5 & 21.0 & 24.1 & & 182 & 23.1 & 21.5 & 24.7 & \\ \text { C-reactive protein (CRP), mg/L } & & & & & & & & & & \\ \leq 3 & 236 & 18.0 & 17.1 & 18.9 & 0.042 & 313 & 19.9 & 18.6 & 21.3 & 0.274 \\ >3 & 76 & 19.4 & 18.0 & 20.9 & & 97 & 20.8 & 19.1 & 22.5 & \end{array}$

Hepatitis B infection

$\begin{array}{lrrrrrrrrrr}\text { No } & 303 & 18.3 & 17.4 & 19.2 & 0.058 & 395 & 20.2 & 18.9 & 21.5 & 0.442 \\ \text { Yes } & 9 & 21.9 & 18.1 & 26.5 & & 14 & 21.7 & 17.9 & 26.2 & \end{array}$

Hepatitis C infection

$\begin{array}{lrrrrrrrrrr}\text { No } & 304 & 18.3 & 17.4 & 19.2 & 0.371 & 405 & 20.2 & 18.9 & 21.5 & 0.667 \\ \text { Yes } & 8 & 20.0 & 16.4 & 24.4 & & 5 & 21.5 & 16.0 & 28.9 & \end{array}$

Hepatitis B or C infection ${ }^{\mathrm{h}}$

\begin{tabular}{lrrrrrrrrrr} 
No & 296 & 18.3 & 17.4 & 19.2 & 0.458 & 390 & 20.2 & 18.9 & 21.5 & 0.369 \\
Yes & 16 & 19.3 & 16.7 & 22.3 & & 19 & 21.7 & 18.3 & 25.6 & \\
\hline
\end{tabular}

a $P$-value for comparison of $\ln (\mathrm{GGT})$ values between men and women, adjusted for fasting status, BMI and country

b Missing $\mathrm{N}=8$

c Missing $\mathrm{N}=164$

$\mathrm{d}$ Missing $\mathrm{N}=29$ (women=21, men=8). Sex-specific tertiles (men: $\leq 0.92,0.92-0.97, \geq 0.97$; women: $\leq 0.77,0.77-0.84, \geq 0.84$ ).

e Based on the assumption that $1 \mathrm{cup}=150 \mathrm{~mL}$;

f Self-reported; missing $N=34$

g Self-reported; missing $\mathrm{N}=150$

$\mathrm{h}$ The numbers of hepatitis B and C infected do not add up because one person had both, hepatitis B and C infections. 
Supplementry table 6: Serum Alkaline phosphatase (ALP) concentrations (IU/L) according to categories of various predictor variables among controls in the EPIC nested case-control study, 1992-2004 (men, $n=410$ and women, $n=312$ ).

\begin{tabular}{|c|c|c|c|c|c|c|c|c|c|c|}
\hline \multirow{3}{*}{ Stratum (ALP) } & \multicolumn{5}{|c|}{ Women $(\mathrm{N}=312)$} & \multicolumn{5}{|c|}{$\operatorname{Men}(\mathrm{N}=410)$} \\
\hline & \multirow{2}{*}{$\frac{\mathrm{N}}{312}$} & \multirow{2}{*}{$\begin{array}{c}\begin{array}{c}\text { Geometric } \\
\text { mean }\end{array} \\
64.1\end{array}$} & \multicolumn{2}{|c|}{$95 \% \mathrm{CI}$} & \multirow{2}{*}{$\begin{array}{l}P \text {-value } \\
---\end{array}$} & \multirow{2}{*}{$\frac{N}{410}$} & \multirow{2}{*}{$\begin{array}{l}\begin{array}{l}\text { Geometric } \\
\text { mean }\end{array} \\
59.3\end{array}$} & \multicolumn{2}{|c|}{$95 \% \mathrm{CI}$} & \multirow{2}{*}{$\begin{array}{r}P \text {-value } \\
0.0011\end{array}$} \\
\hline & & & 61.3 & 66.9 & & & & 56.9 & 61.9 & \\
\hline \multicolumn{11}{|l|}{ Age at blood collection, years } \\
\hline$\leq 55$ & 75 & 55.9 & 51.1 & 61.2 & \multirow[t]{4}{*}{0.0047} & 115 & 59.9 & 56.0 & 64.2 & \multirow[t]{4}{*}{0.9699} \\
\hline $55-60$ & 69 & 66.6 & 60.7 & 73.1 & & 105 & 61.0 & 57.1 & 65.1 & \\
\hline $61-65$ & 113 & 70.0 & 64.6 & 75.8 & & 120 & 59.0 & 55.2 & 63.0 & \\
\hline$>65$ & 55 & 67.1 & 60.5 & 74.3 & & 70 & 60.7 & 56.0 & 65.7 & \\
\hline \multicolumn{11}{|l|}{ Cigarette smoking ${ }^{b}$} \\
\hline Never & 188 & 64.1 & 58.2 & 70.5 & \multirow[t]{3}{*}{0.276} & 123 & 58.7 & 55.4 & 62.2 & \multirow[t]{3}{*}{0.079} \\
\hline Former & 62 & 63.6 & 59.4 & 68.0 & & 176 & 60.0 & 56.3 & 63.9 & \\
\hline Current & 59 & 69.0 & 62.3 & 76.4 & & 106 & 63.1 & 59.1 & 67.3 & \\
\hline \multicolumn{11}{|c|}{ Alcohol consumption at recruitment, $\mathrm{g} / \mathrm{d}$} \\
\hline None & 62 & 67.9 & 61.4 & 75.1 & \multirow[t]{6}{*}{0.447} & 19 & 65.5 & 58.0 & 74.0 & \multirow[t]{6}{*}{0.0232} \\
\hline $0.1-6$ & 129 & 64.7 & 60.0 & 69.7 & & 98 & 62.3 & 58.1 & 66.7 & \\
\hline $6.1-12$ & 46 & 62.5 & 56.0 & 69.6 & & 57 & 62.3 & 57.5 & 67.4 & \\
\hline $12.1-24$ & 55 & 64.0 & 57.7 & 71.0 & & 103 & 59.0 & 55.4 & 62.8 & \\
\hline $24.1-60$ & 20 & 63.3 & 53.7 & 74.6 & & 97 & 57.7 & 53.9 & 61.8 & \\
\hline$>60$ & & & & & & 36 & 60.3 & 54.6 & 66.5 & \\
\hline \multicolumn{11}{|l|}{ Drinking history } \\
\hline Never drinker & 46 & 71.1 & 63.1 & 80.2 & 0.400 & 12 & 62.8 & 53.7 & 73.5 & 0.500 \\
\hline Former drinker & 14 & 63.0 & 52.4 & 75.8 & & 7 & 69.2 & 56.7 & 84.3 & \\
\hline Drinker at recruitment & 83 & 67.2 & 60.5 & 74.7 & & 84 & 60.2 & 54.9 & 66.1 & \\
\hline Lifetime drinker & 169 & 63.4 & 58.7 & 68.4 & & 307 & 59.8 & 56.2 & 63.6 & \\
\hline Body mass index, $\mathrm{kg} / \mathrm{m}^{2}$ & & & & & & & & & & \\
\hline$\leq 25$ & 125 & 59.3 & 54.9 & 64.1 & 0.0004 & 136 & 60.3 & 56.8 & 64.1 & 0.2926 \\
\hline $25-30$ & 129 & 67.3 & 62.5 & 72.4 & & 203 & 59.4 & 56.2 & 62.8 & \\
\hline$\geq 30$ & 58 & 72.6 & 65.8 & 80.0 & & 71 & 62.8 & 58.2 & 67.7 & \\
\hline Waist to hip ratio ${ }^{d}$ & & & & & & & & & & \\
\hline Tertile 1 & 87 & 56.3 & 51.7 & 61.4 & $<.0001$ & 103 & 58.4 & 54.3 & 62.9 & 0.1524 \\
\hline Tertile 2 & 122 & 62.9 & 58.2 & 68.0 & & 171 & 59.5 & 55.6 & 63.8 & \\
\hline Tertile 3 & 82 & 68.6 & 63.2 & 74.4 & & 128 & 61.4 & 56.9 & 66.4 & \\
\hline Coffee consumption, cups/da & & & & & & & & & & \\
\hline None & 19 & 67.3 & 57.5 & 78.7 & 0.9154 & 21 & 61.2 & 54.4 & 68.8 & 0.1906 \\
\hline$<=1$ & 111 & 61.2 & 55.5 & 67.6 & & 144 & 61.1 & 57.3 & 65.2 & \\
\hline$>1-3$ & 68 & 68.9 & 62.9 & 75.5 & & 66 & 60.9 & 56.8 & 65.2 & \\
\hline$>3-5$ & 114 & 61.7 & 55.7 & 68.4 & & 179 & 63.2 & 58.6 & 68.3 & \\
\hline$>5$ & & 67.9 & 59.9 & 76.9 & & & 54.4 & 50.3 & 58.8 & \\
\hline Prevalent diabetes ${ }^{f}$ & & & & & & & & & & \\
\hline No & 284 & 63.8 & 60.0 & 67.9 & 0.009 & 363 & 60.1 & 57.1 & 63.2 & 0.804 \\
\hline Yes & 14 & 82.3 & 68.2 & 99.4 & & 27 & 60.8 & 54.7 & 67.6 & \\
\hline Prevalent CVD ${ }^{g}$ & & & & & & & & & & \\
\hline 150 & 62.8 & 62.8 & 57.2 & 69.0 & 0.023 & 223 & 59.4 & 55.9 & 63.2 & 0.415 \\
\hline 85 & 70.7 & 70.7 & 63.7 & 78.4 & & 114 & 59.8 & 55.9 & 63.9 & \\
\hline Gamma glutamyltransferase ( & GT), & & & & & & & & & \\
\hline$\leq 36 / 64$ & 247 & 62.3 & 58.6 & 66.2 & 0.0001 & 228 & 57.2 & 54.2 & 60.4 & $<0.0001$ \\
\hline
\end{tabular}


$>36 / 64$

65

$\begin{array}{lll}74.5 & 67.9 & 81.6\end{array}$

182

$64.5 \quad 61.0$

68.3

C-reactive protein (CRP), mg/L

$\leq 3$

236

$\begin{array}{lll}62.5 & 58.8 & 66.5\end{array}$

$0.001 \quad 313$

$57.9 \quad 54.9$

$61.0<0.0001$

$>3$

76

$\begin{array}{lll}72.8 & 66.4 & 79.7\end{array}$

97

$65.6 \quad 61.6$

69.8

Hepatitis B infection

$\begin{array}{lrrrrrrrrrr}\text { No } & 303 & 64.7 & 61.0 & 68.6 & 0.729 & 395 & 60.3 & 57.4 & 63.5 & 0.469 \\ \text { Yes } & 9 & 67.4 & 53.2 & 85.4 & & 14 & 57.2 & 49.2 & 66.5 & \\ \text { epatitis C infection } & & & & & & & & & & \\ \text { No } & 304 & 64.8 & 61.1 & 68.8 & 0.672 & 405 & 60.4 & 57.4 & 63.5 & 0.370 \\ \text { Yes } & 8 & 61.5 & 48.1 & 78.6 & & 5 & 54.4 & 43.1 & 68.6 & \end{array}$

Hepatitis B or C infection ${ }^{\mathrm{h}}$

\begin{tabular}{lrrrrrrrrrr} 
No & 296 & 64.7 & 61.0 & 68.6 & 0.855 & 390 & 60.4 & 57.5 & 63.5 & 0.266 \\
Yes & 16 & 65.8 & 55.0 & 78.7 & & 19 & 56.3 & 49.4 & 64.2 & \\
\hline
\end{tabular}

a $P$-value for comparison of $\ln (\mathrm{GGT})$ values between men and women, adjusted for fasting status, BMI and country

b Missing $\mathrm{N}=8$

c Missing $\mathrm{N}=164$

d Missing $N=29$ (women=21, men=8). Sex-specific tertiles (men: $\leq 0.92,0.92-0.97, \geq 0.97$; women: $\leq 0.77,0.77-0.84, \geq 0.84$ ).

e Based on the assumption that $1 \mathrm{cup}=150 \mathrm{~mL}$;

f Self-reported; missing $N=34$

g Self-reported; missing $\mathrm{N}=150$

$\mathrm{h}$ The numbers of hepatitis $\mathrm{B}$ and $\mathrm{C}$ infected do not add up because one person had both, hepatitis B and C infections. 
Supplementary table 7. Association for liver function biomarkers (per 1SD logarithm transformed values) and liver function score with HCC risk separate for men and women.

\begin{tabular}{|c|c|c|c|c|c|c|}
\hline HCC (n $\left.n_{\text {cases }}=121\right)$ & Model 1 & & Model 2 & & Model 3 & \\
\hline Men (ncases $=82)$ & OR & $95 \% \mathrm{CI}$ & OR & $95 \% \mathrm{CI}$ & OR & $95 \% \mathrm{CI}$ \\
\hline GGT & 6.09 & $3.38,10.94$ & 5.84 & $3.01,11.33$ & 4.57 & $2.36,8.84$ \\
\hline ALT & 2.88 & $1.97,4.21$ & 3.01 & $1.87,4.84$ & 2.10 & $1.28,3.46$ \\
\hline AST & 4.08 & $2.60,6.41$ & 4.26 & $2.42,7.50$ & 3.25 & $1.80,5.88$ \\
\hline ALP & 4.46 & $2.71,7.35$ & 4.39 & $2.33,8.27$ & 4.86 & $2.21,10.70$ \\
\hline Bilirubin & 2.12 & $1.50,2.98$ & 2.59 & $1.61,4.18$ & 2.13 & $1.29,3.52$ \\
\hline Liver function score ${ }^{a}$ & 4.25 & $2.55,7.08$ & 4.00 & $2.32,6.92$ & 3.35 & $1.91,5.87$ \\
\hline \multicolumn{7}{|l|}{ Women $\left(\mathbf{n}_{\text {cases }}=37\right)$} \\
\hline GGT & 3.03 & $1.70,5.40$ & 3.03 & $1.70,5.40$ & 3.68 & $1.39,9.73$ \\
\hline ALT & 2.55 & $1.51,4.32$ & 2.55 & $1.51,4.32$ & 2.20 & $0.98,4.92$ \\
\hline AST & 3.33 & $1.73,6.43$ & 3.33 & $1.73,6.43$ & 2.81 & $1.12,7.01$ \\
\hline ALP & 2.09 & $1.30,3.35$ & 2.09 & $1.30,3.35$ & 2.89 & $1.25,6.65$ \\
\hline Bilirubin & 1.89 & $1.15,3.09$ & 1.89 & $1.15,3.09$ & 2.01 & $0.94,4.32$ \\
\hline Liver function score & 2.56 & $1.55,4.23$ & 3.27 & $1.50,7.15$ & 2.67 & $1.13,6.32$ \\
\hline
\end{tabular}

Model 1: matching factors

Model 2: model 1 adjusted for BMI continuous alcohol at recruitment continuous, drinking history, smoking status, physical activity

Model 3: model $2+$ plus hepatitis

${ }^{a}$ Ranges from 0 to 6; based on abnormal liver function tests (ALT>55 U/L, AST >34 U/L, GGT men >64 U/L, GGT women $>36 \mathrm{U} / \mathrm{L}, \mathrm{ALP}>150 \mathrm{U} / \mathrm{L}$, albumin $<34 \mathrm{~g} / \mathrm{L}$, total bilirubin $>20.5 \mu \mathrm{mol} / \mathrm{L}$; values were provided by the laboratory). 
Supplementary table 8. Association for liver function biomarkers (per 1SD logarithm transformed values) and liver function score with GBTC risk separate for men and women.

\begin{tabular}{|c|c|c|c|c|}
\hline \multirow{2}{*}{$\begin{array}{l}\text { GBTC (ncases=131) } \\
\text { Men (ncases }=58)\end{array}$} & \multicolumn{2}{|l|}{ Model 1} & \multicolumn{2}{|l|}{ Model 2} \\
\hline & OR & $95 \% \mathrm{CI}$ & OR & $95 \% \mathrm{CI}$ \\
\hline GGT & 1.54 & $0.93,2.54$ & 1.43 & $0.95,2.13$ \\
\hline ALT & 1.07 & $0.49,2.33$ & 0.96 & $0.64,1.45$ \\
\hline AST & 1.43 & $0.52,3.92$ & 1.09 & $0.77,1.53$ \\
\hline ALP & 14.84 & $3.16,69.80$ & 2.33 & $1.31,4.17$ \\
\hline Bilirubin & 0.78 & $0.35,1.72$ & 0.95 & $0.65,1.40$ \\
\hline Liver function score ${ }^{\mathrm{a}}$ & 1.12 & $0.64,1.95$ & 1.17 & $0.62,2.20$ \\
\hline \multicolumn{5}{|l|}{ Women $\left(\mathbf{n}_{\text {cases }}=73\right)$} \\
\hline GGT & 1.11 & $0.65,1.91$ & 1.00 & $0.68,1.47$ \\
\hline ALT & 1.40 & $0.69,2.86$ & 1.19 & $0.84,1.69$ \\
\hline AST & 1.61 & $0.49,5.30$ & 1.20 & $0.82,1.74$ \\
\hline ALP & 2.21 & $0.83,5.87$ & 1.33 & $0.96,1.85$ \\
\hline Bilirubin & 1.32 & $0.62,2.83$ & 1.17 & $0.83,1.66$ \\
\hline Liver function score & 1.05 & $0.57,1.95$ & 1.02 & $0.53,1.94$ \\
\hline
\end{tabular}

Model 1: matching factors

Model 2: model 1 adjusted for BMI continuous alcohol at recruitment continuous, drinking history, smoking status, physical activity ${ }^{a}$ Ranges from 0 to 6; based on abnormal liver function tests (ALT $>55 \mathrm{U} / \mathrm{L}, \mathrm{AST}>34 \mathrm{U} / \mathrm{L}$, GGT men $>64 \mathrm{U} / \mathrm{L}$, GGT women $>36 \mathrm{U} / \mathrm{L}$, ALP $>150 \mathrm{U} / \mathrm{L}$, albumin $<34 \mathrm{~g} / \mathrm{L}$, total bilirubin $>20.5 \mu \mathrm{mol} / \mathrm{L}$; values were provided by the laboratory). 
Supplementary table 9. HCC, IHBC and GBTC risk by categories of HSI, liver function score, AST/ALT and GGT/ALP ratios.

\begin{tabular}{|c|c|c|c|c|c|c|c|c|c|}
\hline & & \multicolumn{2}{|c|}{ HSI category $^{a}$} & \multicolumn{2}{|c|}{$\begin{array}{l}\text { Liver function score } \\
\text { category }^{b}\end{array}$} & \multicolumn{2}{|c|}{$\begin{array}{l}\text { AST/ALT ratio } \\
\text { category }^{c}\end{array}$} & \multicolumn{2}{|c|}{$\begin{array}{c}\text { GGT/ALP ratio } \\
\text { category } \mathrm{d}\end{array}$} \\
\hline & & OR & $95 \% \mathrm{CI}$ & $\overline{\text { OR }}$ & $95 \% \mathrm{CI}$ & $\overline{\mathrm{OR}}$ & $95 \% \mathrm{CI}$ & $\overline{\mathrm{OR}}$ & $95 \% \mathrm{CI}$ \\
\hline \multirow[t]{2}{*}{ HCC $\left(n_{\text {cases }}=121\right)$} & Model 1 & 1.20 & $0.78,1.86$ & 9.35 & $5.27,16.58$ & 4.53 & $1.59,12.94$ & 10.86 & $3.17,37.15$ \\
\hline & Model 2 & 0.92 & $0.46,1.84$ & 8.61 & $4.50,16.46$ & 5.36 & $1.49,19.35$ & 8.68 & $2.25,33.50$ \\
\hline \multirow[t]{2}{*}{$\operatorname{IHBC}^{\mathrm{d}}\left(\mathbf{n}_{\text {cases }}=35\right)$} & Model 1 & 2.95 & $1.18,7.33$ & 3.53 & $1.33,9.40$ & - & - & - & - \\
\hline & Model 2 & 2.76 & $0.60,12.79$ & 4.45 & $1.17,16.98$ & - & - & - & - \\
\hline \multirow[t]{2}{*}{ GBTC $^{e}\left(n_{\text {cases }}=131\right)$} & Model 1 & 1.00 & $0,64,1.59$ & 0.97 & $0.52,1.80$ & 1.70 & $0.54,5.39$ & 0.50 & $0.06,4.47$ \\
\hline & Model 2 & 0.72 & $0.37,140$ & 0.92 & $0.49,1.73$ & 2.07 & $0.61,7.01$ & 0.59 & $0.06,5.79$ \\
\hline
\end{tabular}

HCC, hepatocellular carcinoma; IHBC, intrahepatic bile duct cancer; GBTC, gallbladder and biliary tract cancer

${ }^{a}$ Hepatic steatosis index $(\mathrm{HSI})=8 \times$ ALT/AST ratio + BMI $(+2$, if diabetes; +2 ; if female), HSI $<36$ (reference; liver steatosis unlikely) and $\geq 36$ (suspected liver steatosis)

${ }^{\mathrm{b}}$ Liver function score is based on abnormal liver function tests (ALT $>55 \mathrm{U} / \mathrm{L}, \mathrm{AST}>34 \mathrm{U} / \mathrm{L}, \mathrm{GGT}$ men $>64 \mathrm{U} / \mathrm{L}, \mathrm{GGT}$ women $>36 \mathrm{U} / \mathrm{L}, \mathrm{ALP}>150 \mathrm{U} / \mathrm{L}$, albumin $<34 \mathrm{~g} / \mathrm{L}$, total bilirubin $>20.5 \mu \mathrm{mol} / \mathrm{L}$; values were provided by the laboratory). The liver function score was grouped into two categories: 0 (reference) or $1-6$ abnormal liver function tests.

c AST/ALT ratio categories: $<2$ (reference) and $>2$; ratio $>2$ may signalise alcoholic liver disease

${ }^{\mathrm{d}}$ AST/ALT ratio categories: $\leq 2.5$ (reference) and $>2.5$; ratio $>2.5$ may indicate liver cirrhosis

${ }^{e}$ not enough subjects in the upper category for AST/ALP ratio $(n=2)$ and GGT/ALP ratio $(n=1)$ 


\section{SUPPLEMENTARY FIGURES}

Supplementary Fig. 1: Loess curves for HCC of log-transformed standardised levels (rescaled to have a mean of 0 and a SD of 1) of liver biomarkers (GGT, AST, ALT, ALP, bilirubin and AFP) by the time of follow up. Follow up time length of the HCC cases was assigned to their controls for better visualization of the data.
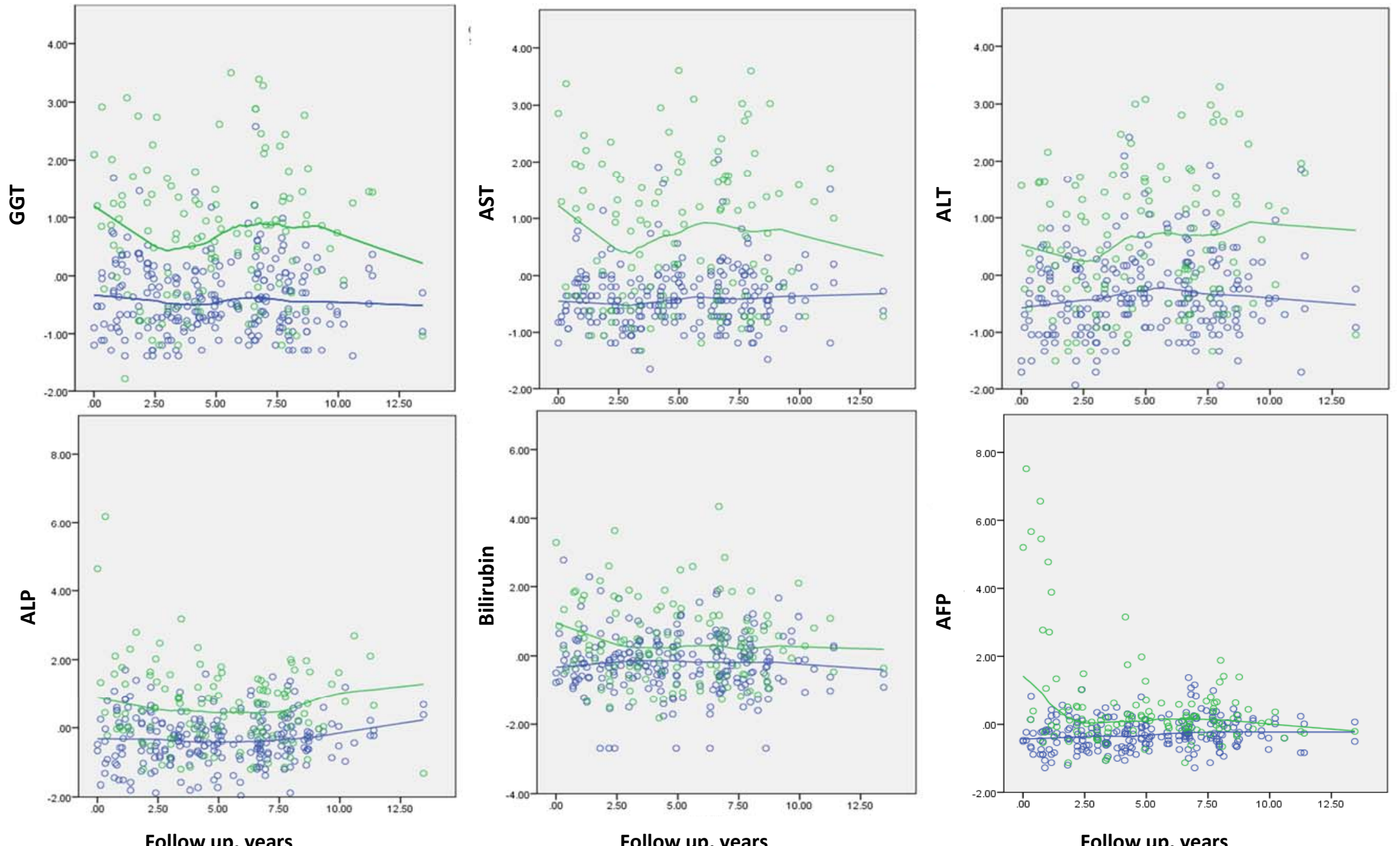

HCC cases

Controls

Follow up, years

Follow up, years

Follow up, years 
Supplementary Fig. 2. Area under receiver operating characteristic curve (AUROC) based only on stepwise selection of liver function biomarkers and corresponding sensitivity and specificity in validation data.

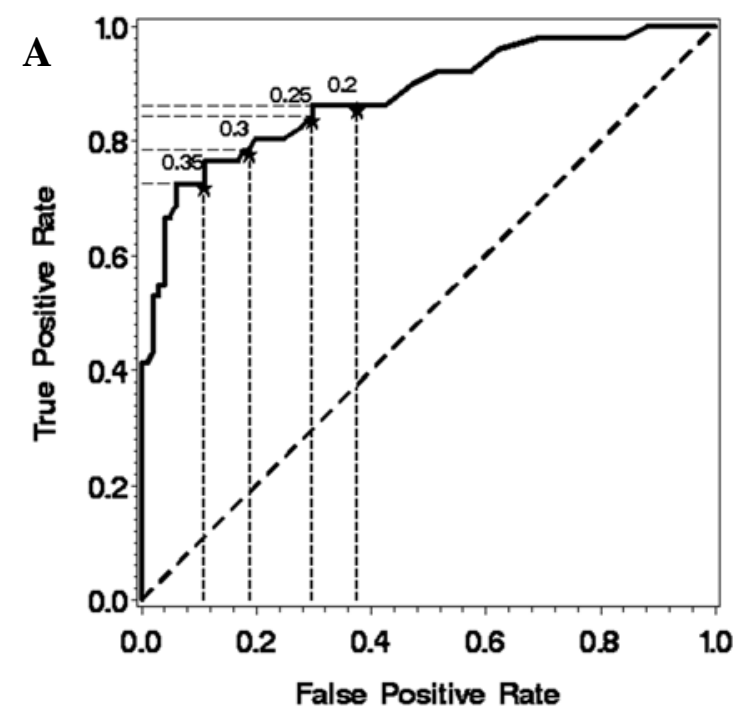

B

\section{AUROC $(95 \% \mathrm{Cl})$ Sensitivity Specificity} (true positive rate) (false positive rate)

\begin{tabular}{llll}
\hline GGT, AST, ALT & $0.88(0.82,0.94)$ & 0.78 & 0.81 \\
\hline
\end{tabular}

AUROC displays the discriminatory accuracy for predicting the development of HCC. Independent liver function biomarkers were selected with a stepwise selection method based on c-statistic. Sensitivity indicates the probability of correctly selecting prospective HCC cases. Specificity indicates the probability of correctly selecting controls. Red points indicate the threshold probabilities for which sensitivity and specificity points were selected based on the shortest distance for a perfect marker. 
Supplementary Fig. 3 Cubic splines for the dose-response associations for log-transformed levels of ALT, ALP, AST and Bilirubin and HCC risk. Adjusted OR and 95\%CI (dashed lines) were constructed with 3 knots with the reference value set as median.
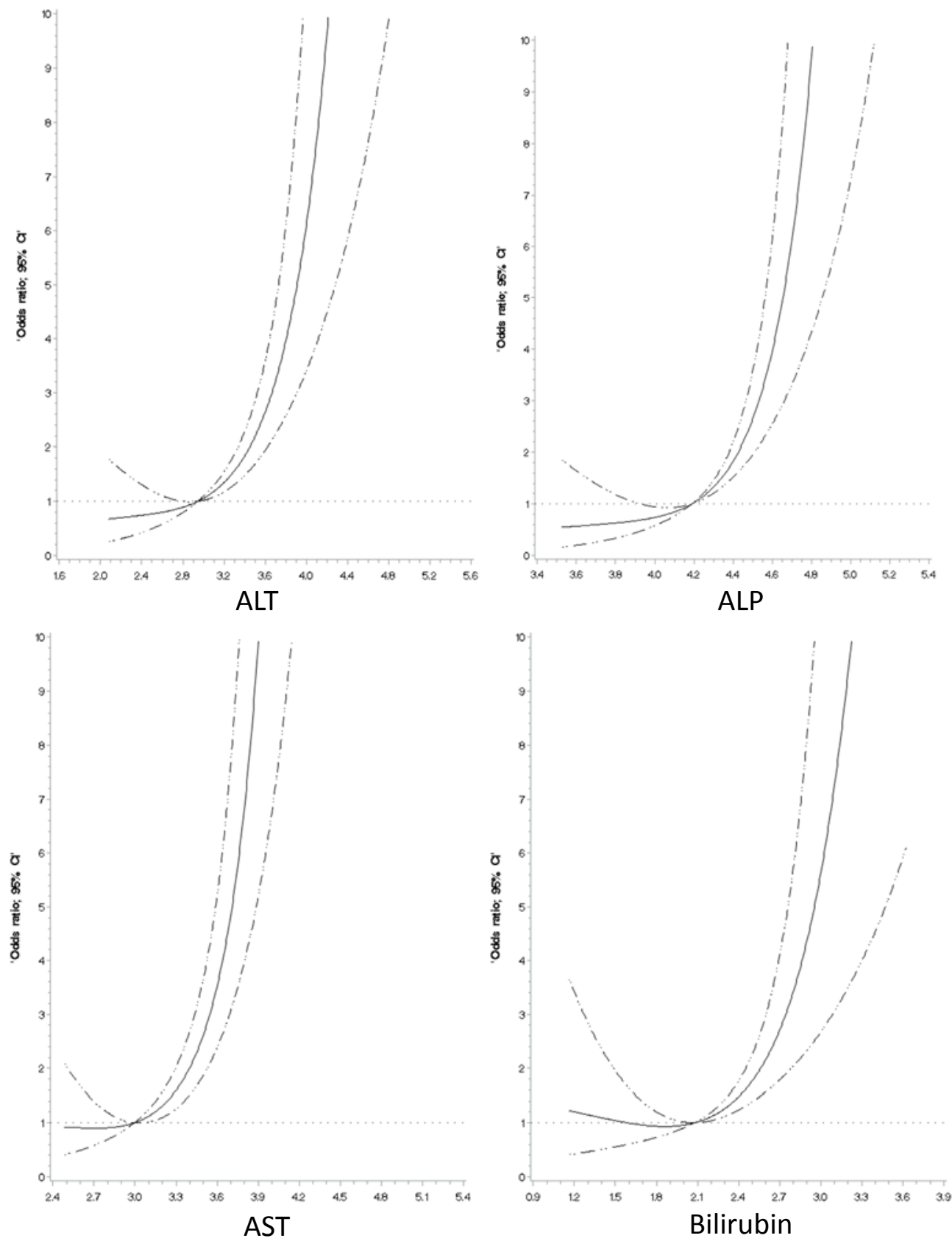